\title{
High-Throughput Synthesis and Screening of Cyclic Peptide Antibiotics
}

\author{
Qing Xiao and Dehua Pei*
}

\section{(Supporting Information)}

Table S1. Cyclization efficiency of 30 randomly selected beads from the tyrocidine analogue library and analyzed by MALDI-TOF MS.

Table S2. Antimicrobial activity of crude resynthesized peptides.

Figure S1. MALDI-TOF spectra of the peptides released from 5 randomly selected beads from the tyrocidine analogue library. The spectra show that the peptides were essentially free of impurities.

Figure S2. PED/MS spectra of the 21 selected cyclic peptides. After screening, the positive beads were retrieved from the 96-well plates and subjected to partial Edman degradation. The resulting peptides were dissolved in $0.1 \%$ TFA in water. One $\mu \mathrm{L}$ of the peptide solution was mixed with $2 \mu \mathrm{L}$ of saturated $\alpha$-cyano-4-hydroxycinnamic acid in acetonitrile $/ 0.1 \%$ TFA in $\mathrm{H}_{2} \mathrm{O}$ (1:1) and $1 \mu \mathrm{L}$ of the mixture was spotted onto a MALDI sample plate. The peptide sequence and the observed $\mathrm{m} / \mathrm{z}$ values are indicated in each spectrum. Nle, norleucine; Fpa L-p-fluorophenylalanine; O, L-ornithine; Sar, sarcosine; Phg, L-phenylglycine.

Figure S3. HPLC analysis of crude resynthesized tyrocidine A analogues. HPLC conditions: HPLC was run on $\mathrm{C}_{18}$ column (Varian Dynamax $250 \times 10.0 \mathrm{~mm}$ ). The crude peptides were dissolved in DMSO and $\mathrm{H}_{2} \mathrm{O}$ before injection. The column was eluted with a linear gradient formed by A: $0.05 \%$ TFA in water and B: $0.05 \%$ TFA in acetonitrile, as indicated in each chromatogram, and was monitored at $214 \mathrm{~nm}$ by Waters 486 tunable absorbance detector. Flow rate was $2 \mathrm{~mL} / \mathrm{min}$.

Figure S4. HPLC chromatogram and MALDI-TOF MS spectra of purified peptides. HPLC was run on $\mathrm{C}_{18}$ column (Vydac 218TP54; $250 \times 4.6 \mathrm{~mm}$ ) with a linear gradient of $20-100 \%$ acetonitrile in $\mathrm{H}_{2} \mathrm{O}$ with $0.05 \%$ TFA over 30 min. The elution was monitored at $214 \mathrm{~nm}$ by Waters 486 tunable absorbance detector. Water soluble peptides were dissolved in $80 \% \mathrm{H}_{2} \mathrm{O}$ and $20 \%$ acetonitrile with $0.05 \%$ TFA before injection. Insoluble peptides were dissolved in DMSO then diluted with $80 \% \mathrm{H}_{2} \mathrm{O}$ and $20 \%$ acetonitrile with $0.05 \%$ TFA before injection. Flow rate was $1 \mathrm{~mL} / \mathrm{min}$. 
Table S1. Cyclization Efficiency of 30 Randomly Picked Beads as Analyzed by MALDI-TOF MS

\begin{tabular}{|c|c|c|c|c|c|c|c|c|c|c|c|c|c|c|c|}
\hline bead & $\begin{array}{c}\mathrm{M}+218 \\
\text { (cyclic + linker) }\end{array}$ & area & $\begin{array}{c}M+236 \\
\text { (uncyclized + linker) }\end{array}$ & area & $\begin{array}{l}\text { uncyclized } \\
(\%)\end{array}$ & $\begin{array}{l}\mathrm{M}+1 \\
\text { (cyclic) }\end{array}$ & area & $\begin{array}{l}2 \mathrm{M}+1 \\
\text { dimer }\end{array}$ & area & $2 M+218$ & area & $2 M+435$ & area & $\begin{array}{c}\text { cyclic } \\
\text { monomer (\%) }\end{array}$ & $\begin{array}{c}\text { cyclic } \\
\text { dimer (\%) }\end{array}$ \\
\hline C1 & 1467.3 & 3006 & 1485.4 & 46 & 1.4 & 1250.4 & 164 & ND & & 2717.6 & 5 & 2934.6 & 2 & 98.4 & 0.2 \\
\hline $\mathrm{C} 2$ & 1489.4 & 1297 & ND & & & 1272.4 & 40 & ND & & ND & & ND & & 100 & \\
\hline C3 & 1536.7 & 3947 & ND & & & 1319.6 & 439 & ND & & ND & & ND & & 100 & \\
\hline C4 & 1454.7 & 2784 & ND & & & 1237.6 & 446 & ND & & ND & & ND & & 100 & \\
\hline C5 & 1591.8 & 4492 & 1609.8 & 54 & 1.2 & 1374.7 & 57 & ND & & ND & & ND & & 98.8 & \\
\hline C6 & 1477.7 & 1433 & ND & & & 1260.6 & 26 & ND & & ND & & ND & & 100 & \\
\hline $\mathrm{C} 7$ & 1529.8 & 2142 & ND & & & 1312.7 & 57 & ND & & ND & & ND & & 100 & \\
\hline $\mathrm{C} 8$ & 1521.8 & 753 & ND & & & 1304.7 & 11 & ND & & ND & & 3044.0 & 16 & 97.9 & 2.1 \\
\hline $\mathrm{C9}$ & 1375.8 & 3068 & 1393.8 & 190 & 5.0 & 1158.7 & 517 & ND & & ND & & ND & & 95.0 & \\
\hline C10 & 1412.9 & 4766 & 1430.9 & 49 & 0.9 & 1195.8 & 536 & ND & & ND & & ND & & 99.1 & \\
\hline C11 & 1460.9 & 1352 & 1478.6 & 83 & 5.3 & 1243.8 & 24 & 2487.7 & 49 & 2704.8 & 49 & ND & & 88.4 & 6.3 \\
\hline C12 & 1446.9 & 6964 & 1464.9 & 138 & 1.8 & 1229.8 & 560 & ND & & ND & & ND & & 98.2 & \\
\hline C13 & 1567.0 & 4394 & 1585.0 & 105 & 2.2 & 1349.9 & 269 & ND & & ND & & ND & & 97.8 & \\
\hline C14 & 1498.1 & 4933 & 1516.1 & 85 & 1.6 & 1280.9 & 53 & ND & & 2778.3 & 83 & 2995.5 & 303 & 91.4 & 7.1 \\
\hline C16 & 1508.1 & 3974 & 1562.2 & 138 & 2.9 & 1291.0 & 146 & ND & & 2798.4 & 48 & 3015.5 & 426 & 87.1 & 10.0 \\
\hline C17 & 1443.1 & 2675 & ND & & & 1225.9 & 58 & ND & & ND & & ND & & 100 & \\
\hline C18 & 1432.0 & 1033 & ND & & & 1214.9 & 267 & ND & & ND & & ND & & 100 & \\
\hline C19 & 1522.1 & 55 & ND & & & 1305.0 & 22 & ND & & ND & & ND & & 100 & \\
\hline C20 & 1481.1 & 9396 & 1499.1 & 191 & 1.9 & 1263.9 & 219 & ND & & ND & & 2962.6 & 192 & 96.2 & 1.9 \\
\hline C21 & 1387.0 & 3638 & ND & & & 1169.9 & 93 & ND & & 2557.0 & 74 & 2774.1 & 134 & 94.7 & 5.3 \\
\hline $\mathrm{C} 22$ & 1401.0 & 3031 & ND & & & 1183.8 & 77 & ND & & ND & & ND & & 100 & \\
\hline $\mathrm{C} 23$ & 1535.1 & 4730 & 1553.1 & 119 & 2.3 & 1318.0 & 274 & ND & & ND & & ND & & 97.7 & \\
\hline $\mathrm{C} 24$ & 1429.0 & 8892 & 1447.0 & 328 & 3.4 & 1211.9 & 475 & ND & & ND & & ND & & 96.6 & \\
\hline D1 & 1495.4 & 164 & ND & & & 1278.3 & 4 & ND & & ND & & ND & & 100 & \\
\hline D2 & 1531.6 & 973 & ND & & & 1314.6 & 49 & ND & & ND & & ND & & 100 & \\
\hline D3 & 1524.7 & 5063 & 1542.7 & 77 & 1.5 & 1307.6 & 169 & ND & & ND & & ND & & 98.5 & \\
\hline D4 & 1476.7 & 7318 & 1494.8 & 142 & 1.8 & 1259.7 & 408 & ND & & ND & & ND & & 98.2 & \\
\hline D6 & 1386.6 & 1890 & ND & & & 1169.5 & 23 & ND & & 2378.4 & 433 & 2774.6 & 148 & 76.7 & 23.3 \\
\hline D7 & 1412.8 & 1593 & 1430.8 & 64 & 3.6 & 1195.7 & 108 & ND & & ND & & ND & & 96.4 & \\
\hline D8 & 1513.9 & 6117 & 1531.9 & 122 & 1.9 & 1296.8 & 271 & ND & & ND & & ND & & 98.1 & \\
\hline avarage & & & & & 1.3 & & & & & & & & & 96.8 & 1.9 \\
\hline
\end{tabular}

Key: m/z M+1, cyclic monomer without the HMBA-homoserine lactone linker; m/z M+218, cyclic monomer + linker, m/z M+236,

linear peptide (uncyclized); m/z 2M+1, cyclic dimer without linker; $\mathrm{m} / \mathrm{z} 2 \mathrm{M}+218$, cyclic dimer + 1 linker; $\mathrm{m} / \mathrm{z} 2 \mathrm{M}+435$,

cyclic dimer +2 linkers. Yield of cyclic monomer $\left(\frac{\circ}{0}\right)=100 \mathrm{x}[\operatorname{areas}$ of $\mathrm{m} / \mathrm{z}(\mathrm{M}+1)+(\mathrm{M}+218)] /[\mathrm{m} / \mathrm{z}(\mathrm{M}+1)+(\mathrm{M}+218)+(\mathrm{M}+236)$

$+(2 \mathrm{M}+1)+(2 \mathrm{M}+218)+(2 \mathrm{M}+435)]$. 
Table S2. Antimicrobial Activity of Crude Resynthesized Peptides ${ }^{a}$

\begin{tabular}{cccccc}
\hline \multirow{2}{*}{ Bead No. } & \multicolumn{3}{c}{ Peptide sequence } & \multicolumn{2}{c}{ MIC $(\mu \mathrm{g} / \mathrm{mL})$} \\
\cline { 2 - 6 } & $\mathrm{X}^{1}$ & $\mathrm{X}^{2}$ & $\mathrm{X}^{3}$ & B. subtilis & E. coli \\
\hline 2 & D-Lys & L-Fpa & L-Pro & 8 & 32 \\
4 & D-Lys & L-Lys & L-Tyr & 2 & 8 \\
9 & D-Arg & D-Leu & D-Asn & 8 & 32 \\
12 & D-Arg & D-Al & L-Pro & 2 & 32 \\
13 & D-Arg & Gly & L-Fpa & 2 & 16 \\
14 & D-Arg & L-Arg & L-Fpa & $0.5-1$ & 4 \\
15 & D-Arg & L-Ser & L-Fpa & $1-2$ & 8 \\
16 & D-Arg & L-Lys & D-Leu & 2 & 32 \\
17 & D-Phe & D-Phe & Sar & 32 & 8 \\
20 & D-Phe & L-Lys & Gly & 2 & 32 \\
\hline
\end{tabular}

${ }^{a}$ The MIC values were calculated on the basis of peptide purity of $\sim 50 \%$. 
Figure S1
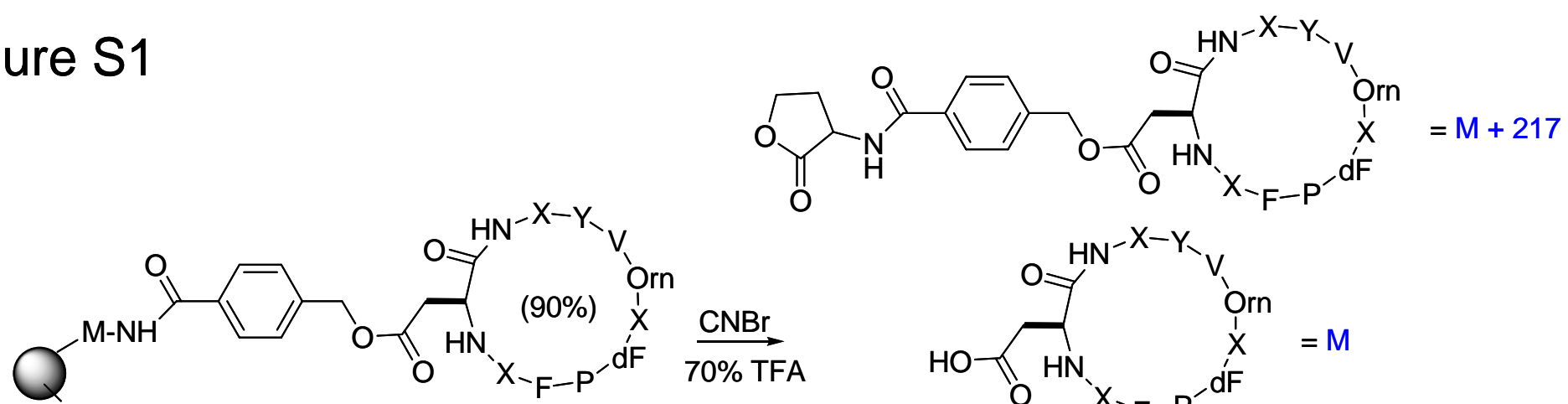

M-K-XFPdFXOrnVYX-NH

R-AC (10\%)
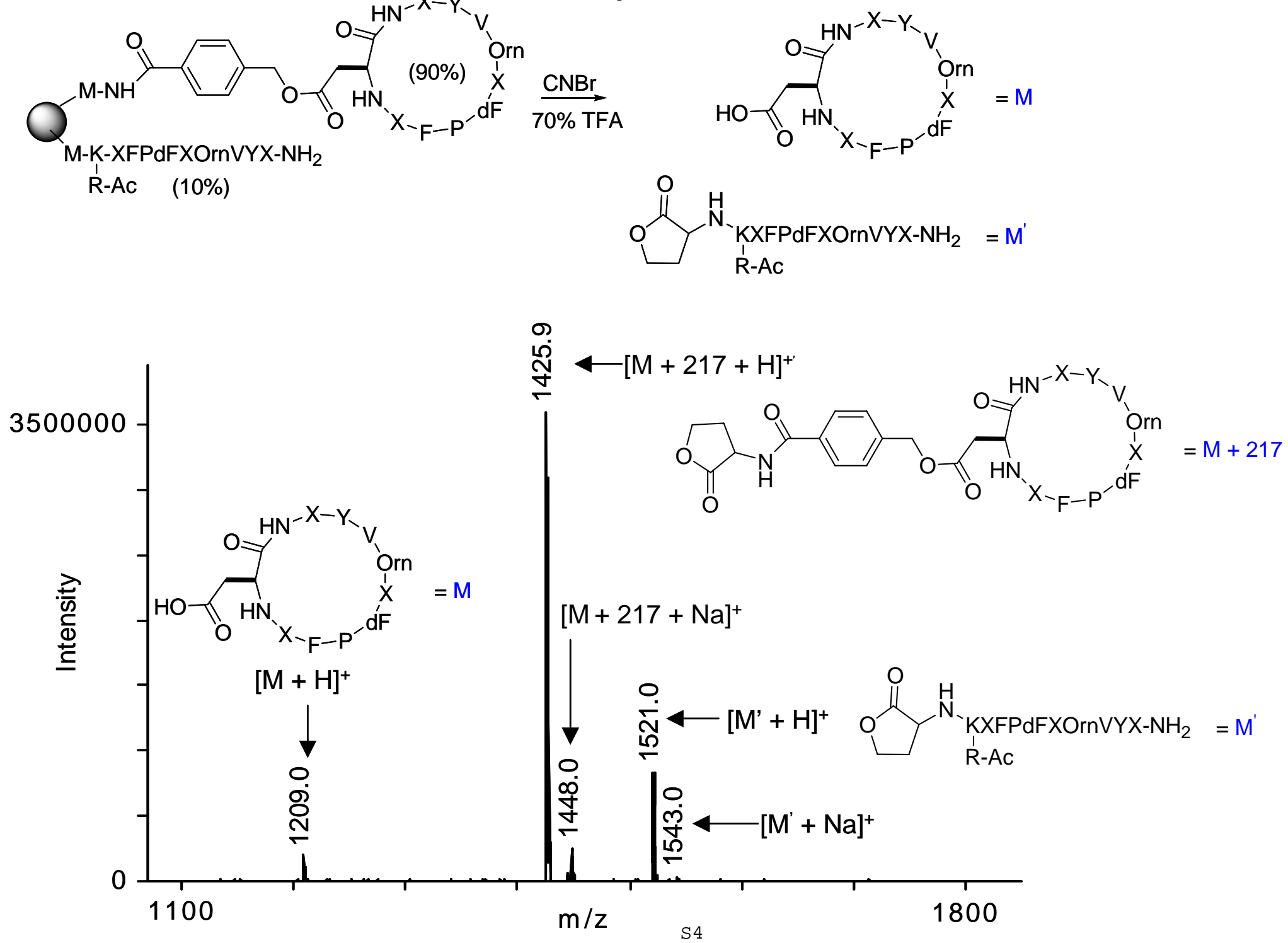


\section{Figure S1 cont'd}
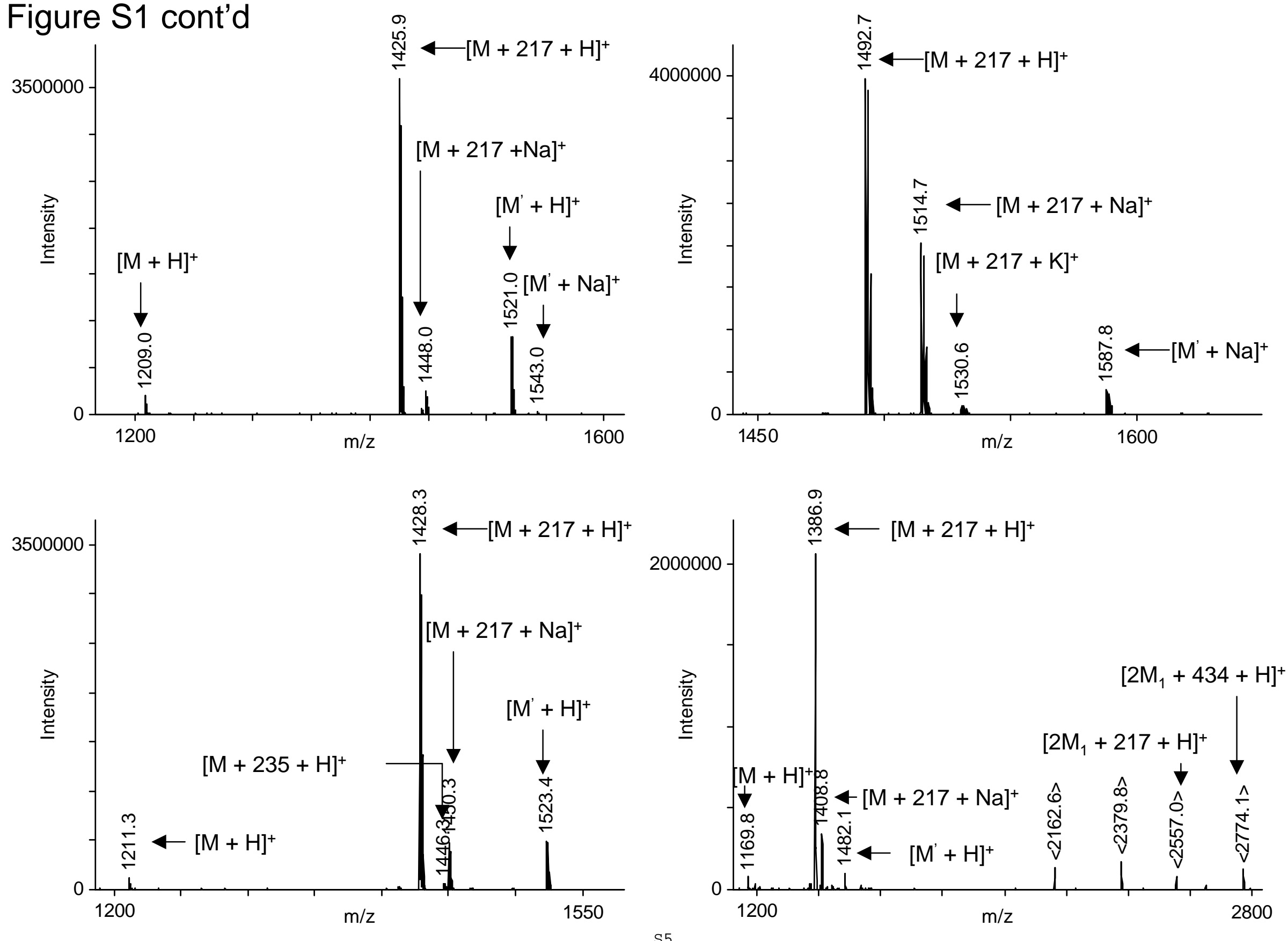
Figure S2. PED/MS spectra of the 21 selected tyrocidine analogues
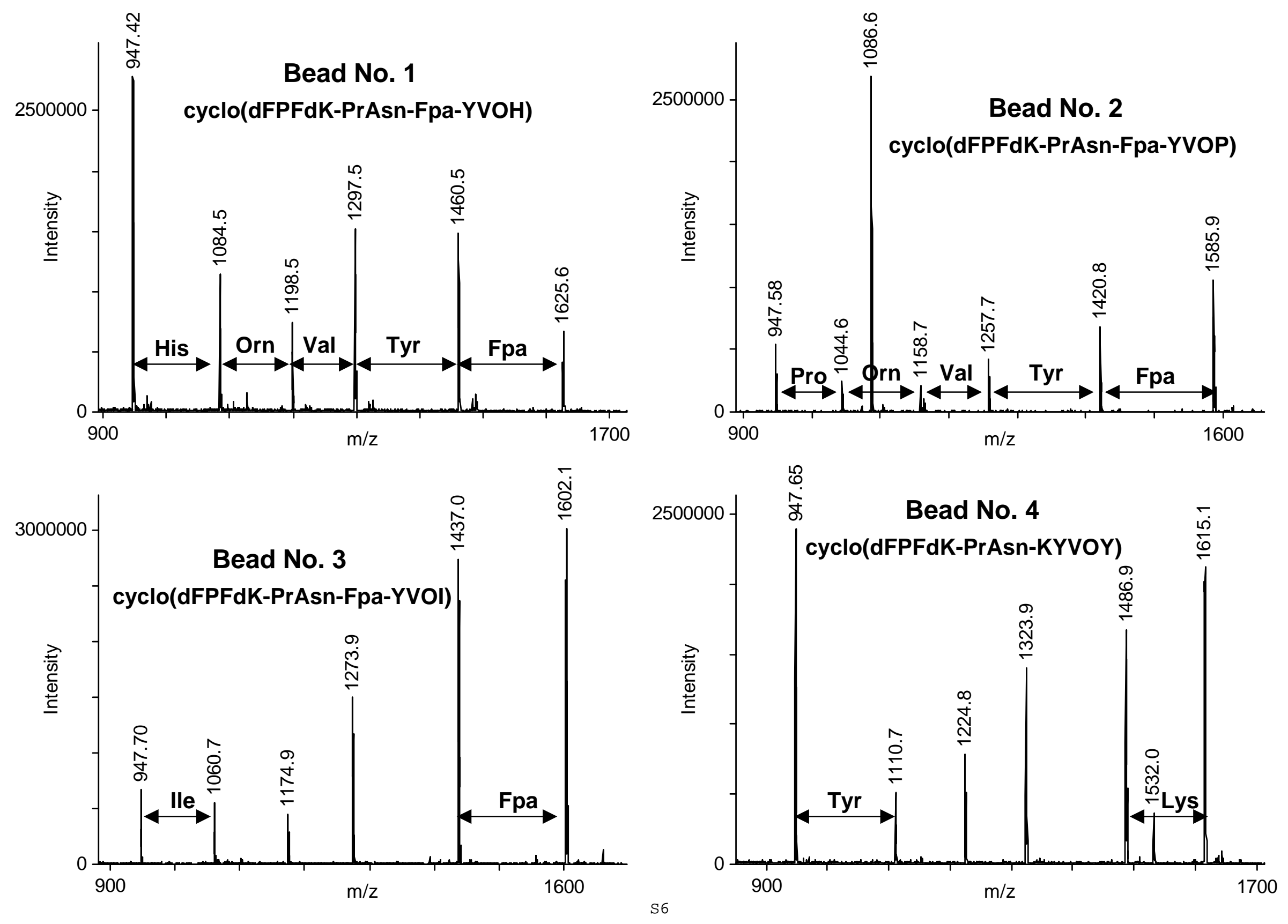
Figure S2 cont'd
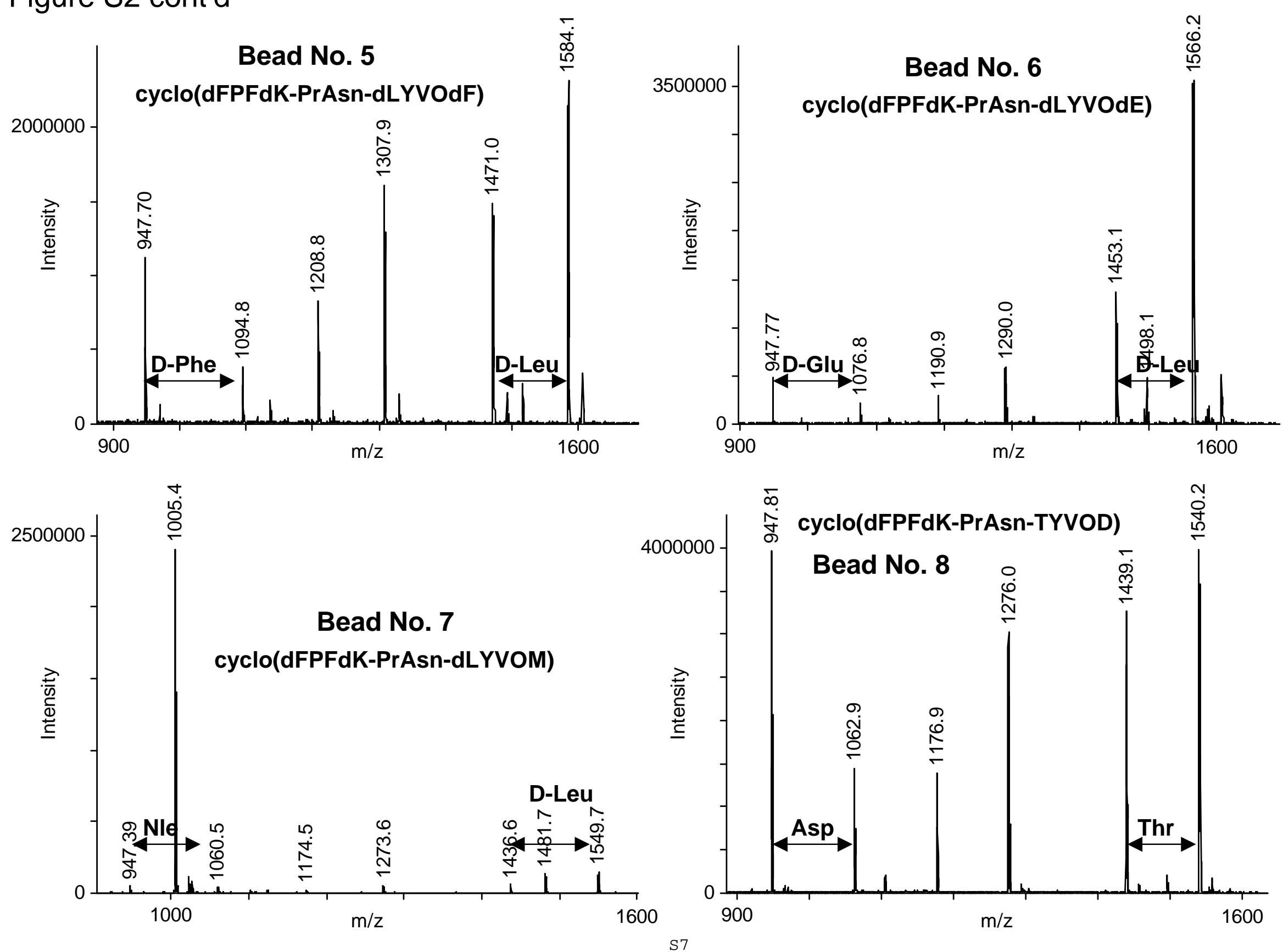
Figure S2 cont'd
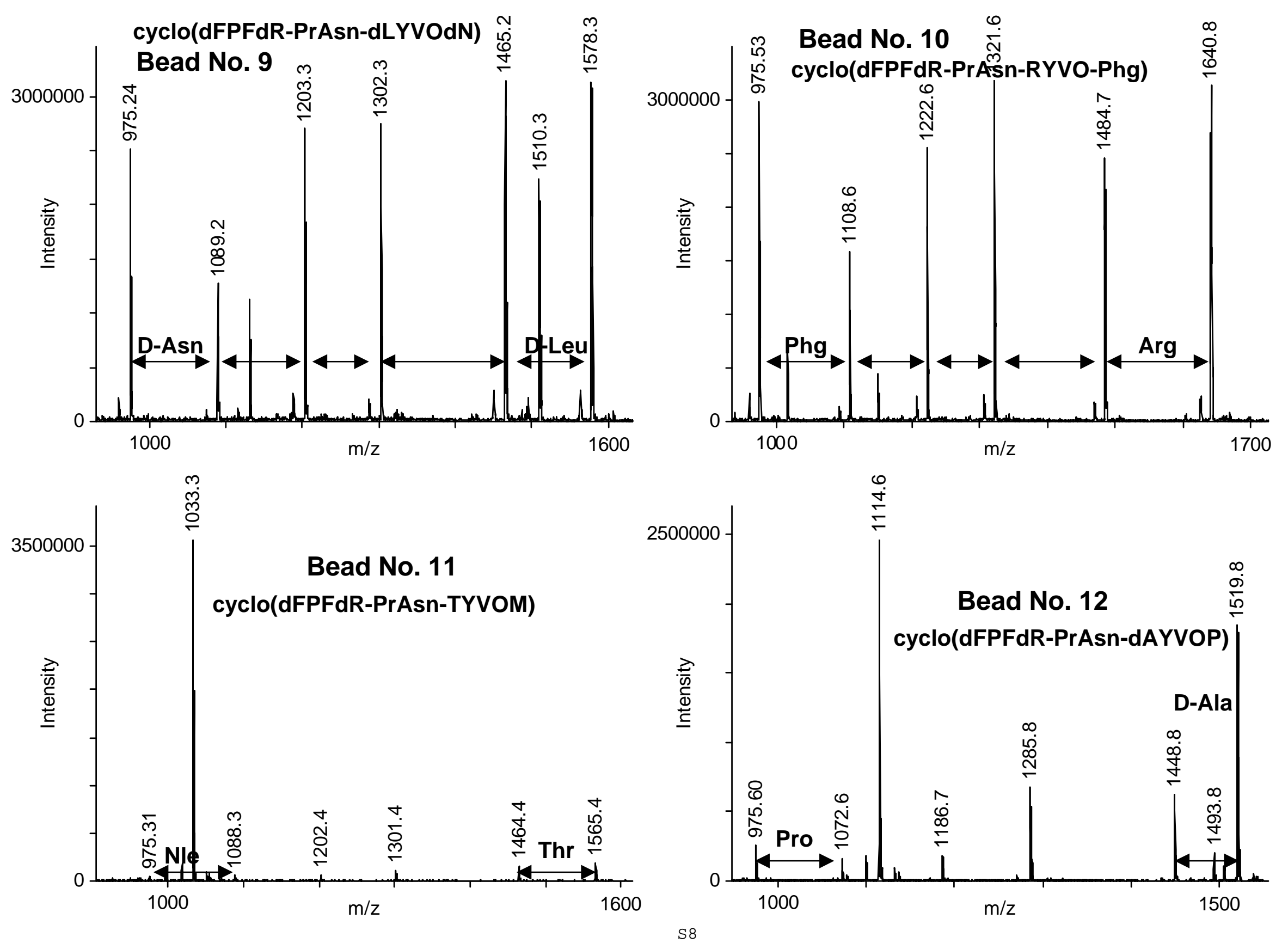
Figure S2 cont'd
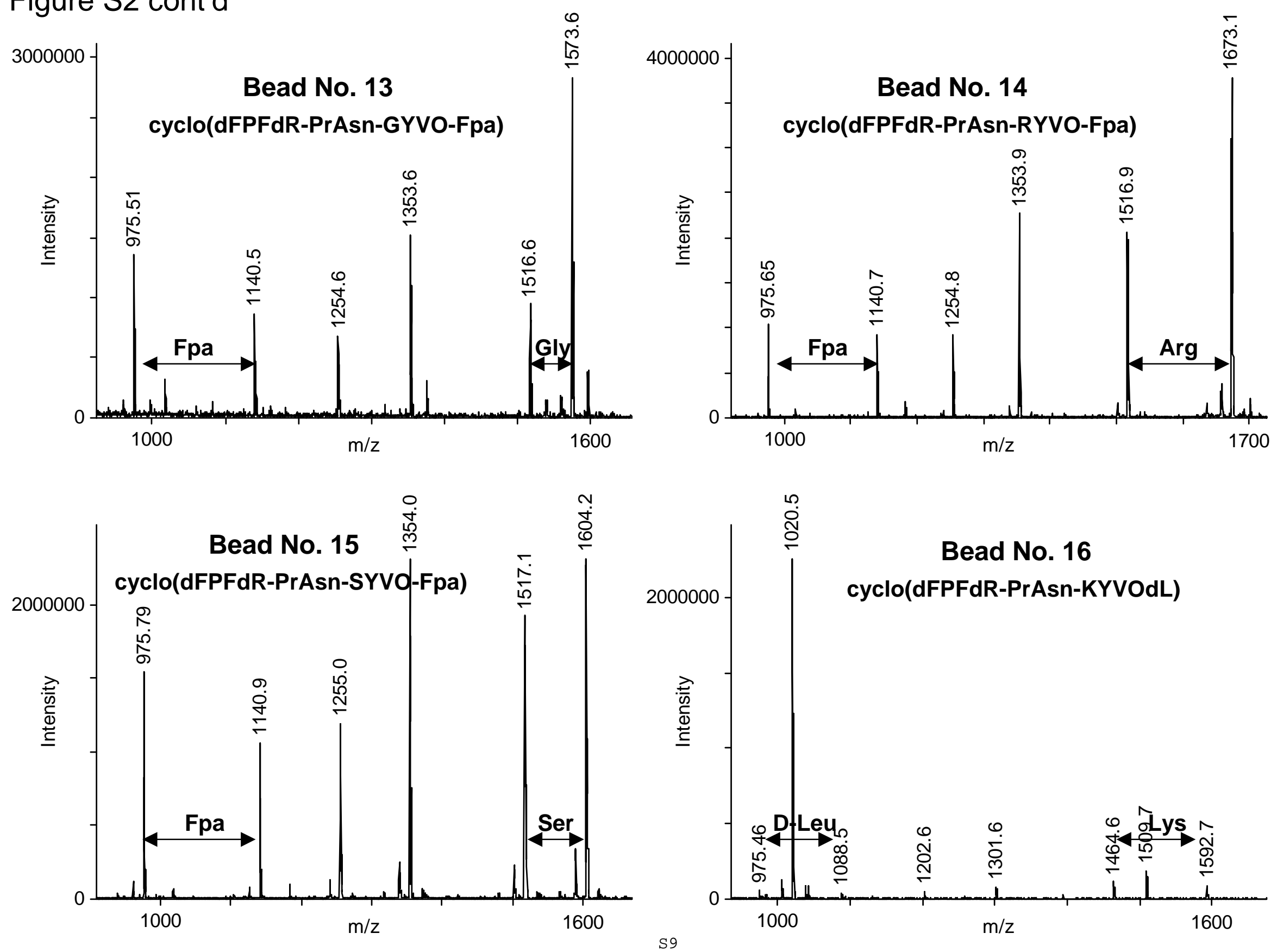
Figure S2 cont'd
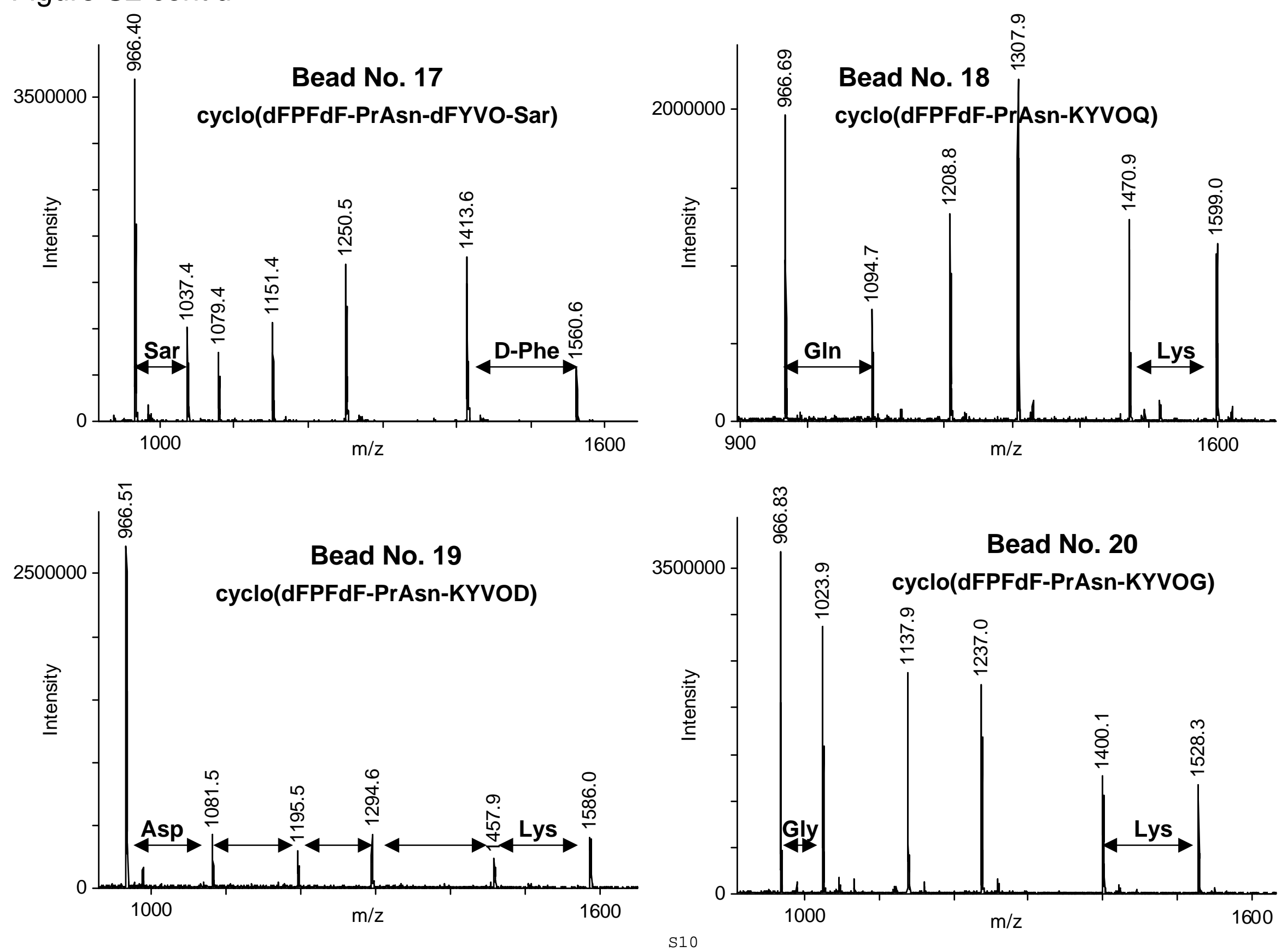


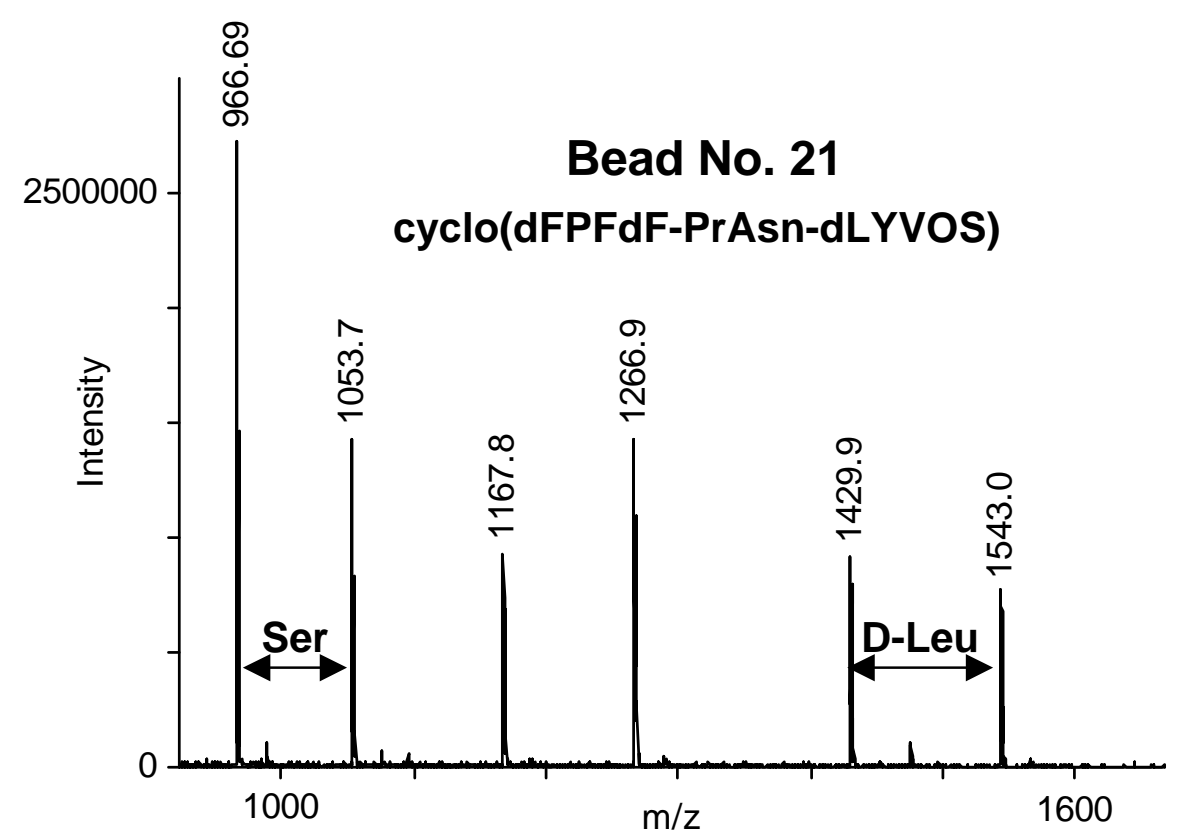


Figure S3. HPLC analysis of Crude Tyrocidine A analogues

2b and 8a: D-Lys ${ }^{4}-F^{2} a^{6}-P^{10}{ }^{10}$

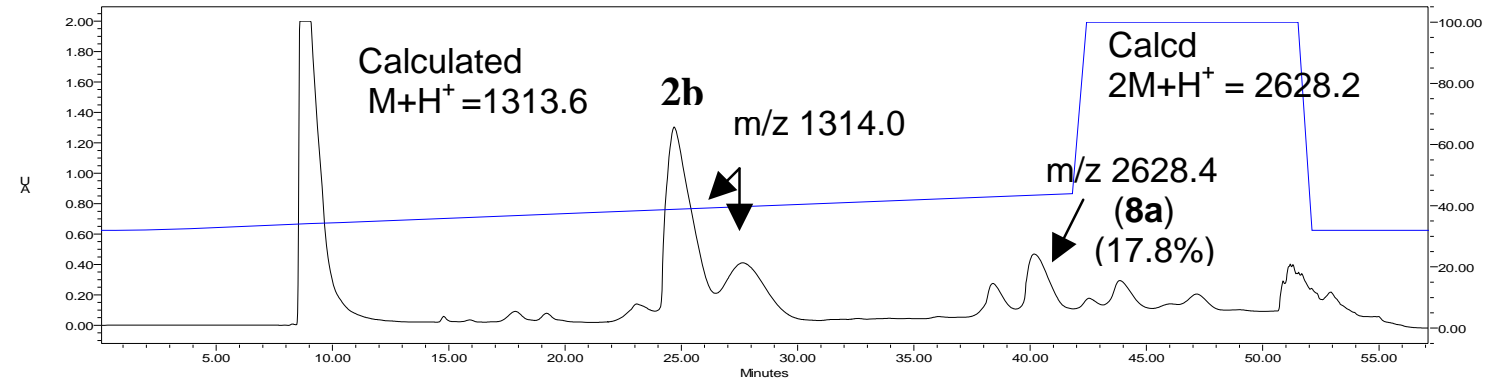

2d and 2e: D-Lys ${ }^{4}-$ Lys $^{6}-$ Tyr $^{10}$

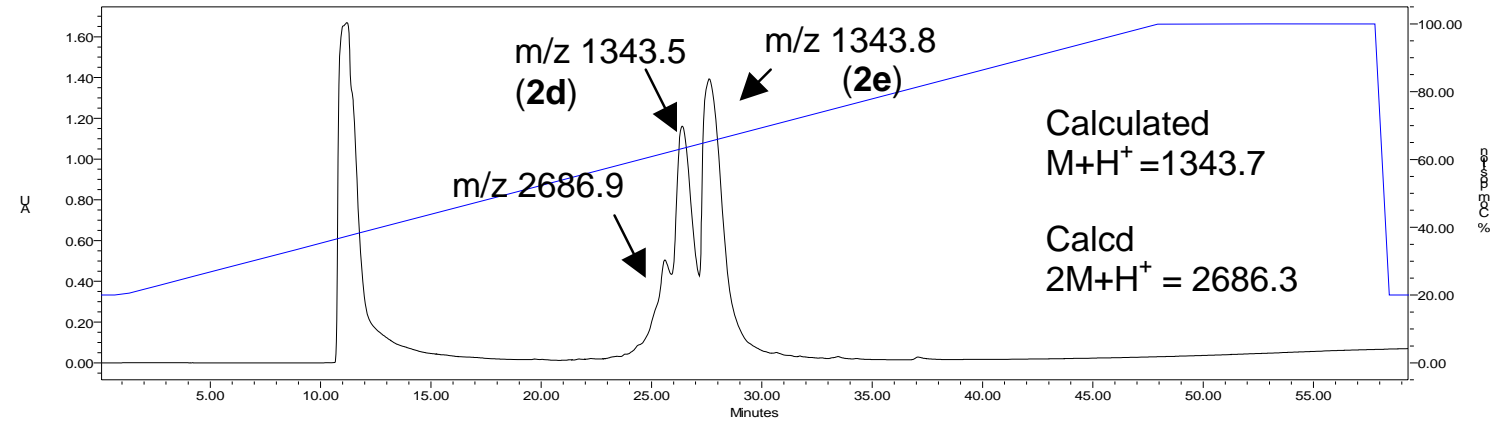

2j: D-Arg ${ }^{4}-D-$ Leu $^{6}-\mathrm{D}-\mathrm{Asn}^{10}$

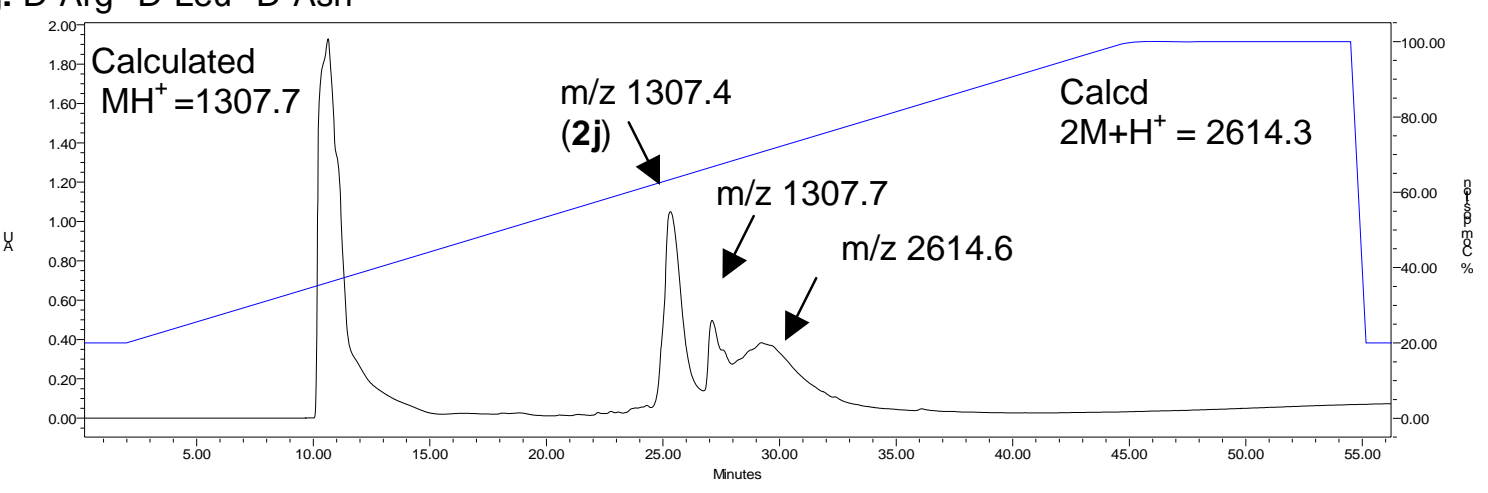

2m and 8b: D-Arg ${ }^{4}$-D-Ala ${ }^{6}-$ Pro $^{10}$

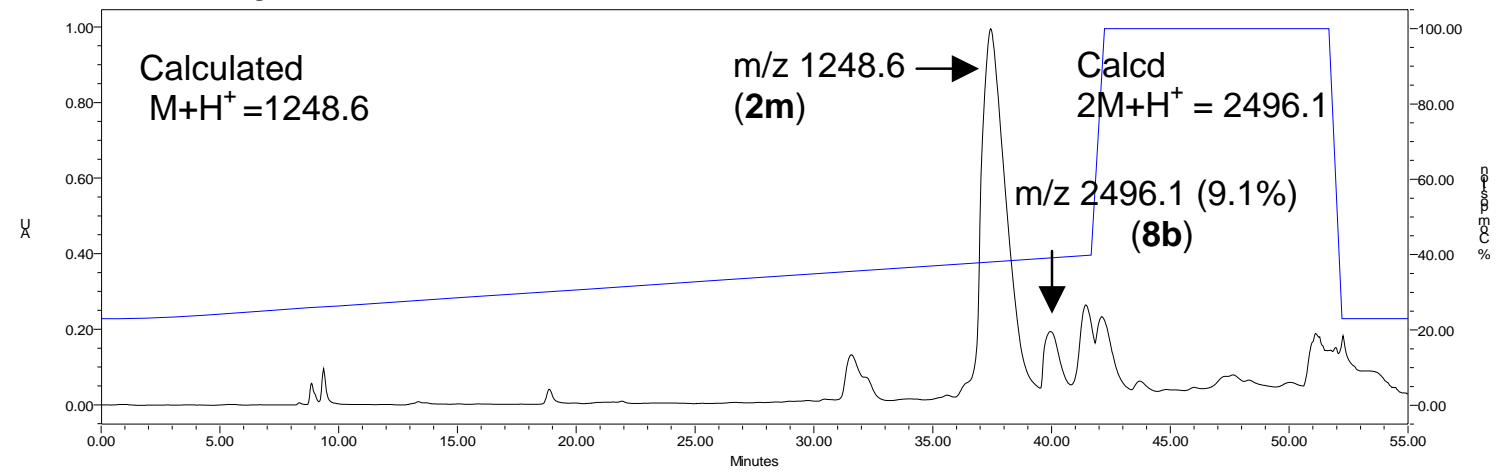


2n and 2o: D-Arg ${ }^{4}-\mathrm{Gly}^{6}-\mathrm{Fpa}^{10}$

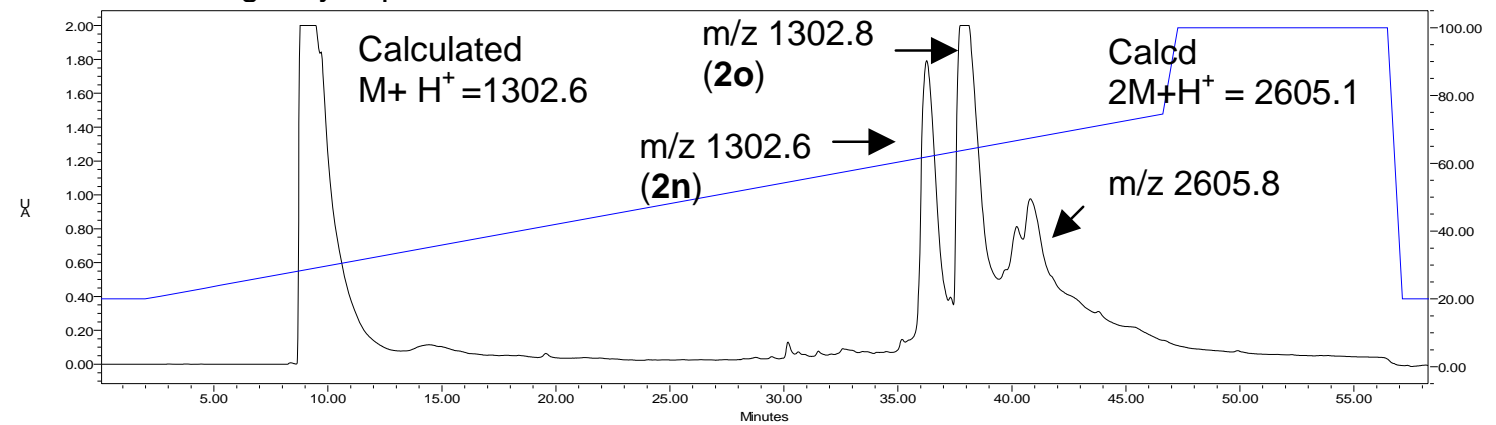

2p and 2q: D-Arg ${ }^{4}-\mathrm{Arg}^{6}-\mathrm{Fpa}^{10}$

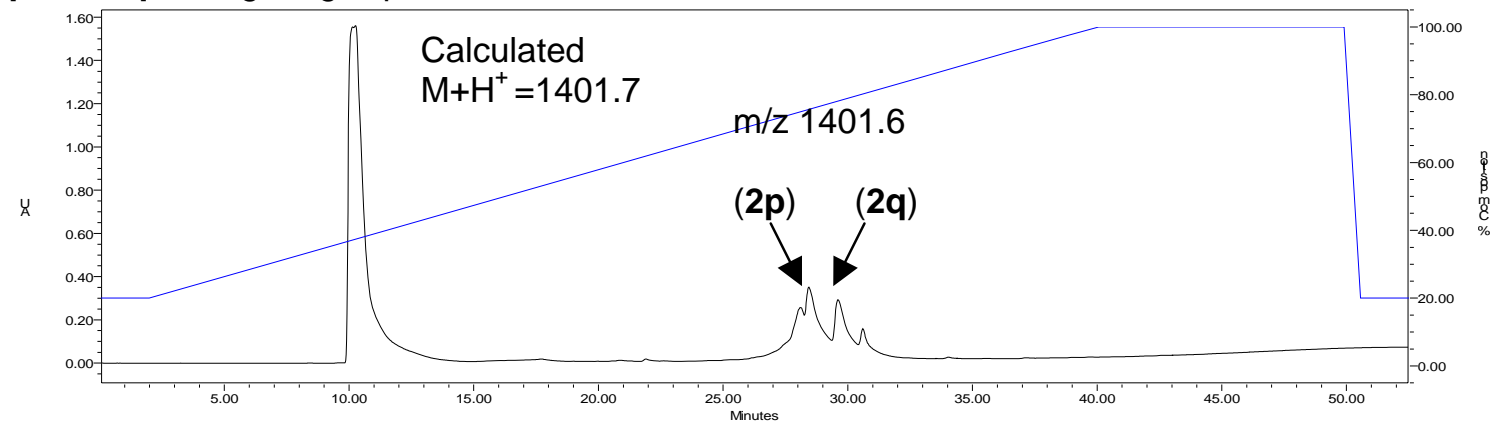

2r and 2s: D-Arg ${ }^{4}-\mathrm{Ser}^{6}-\mathrm{Fpa}^{10}$

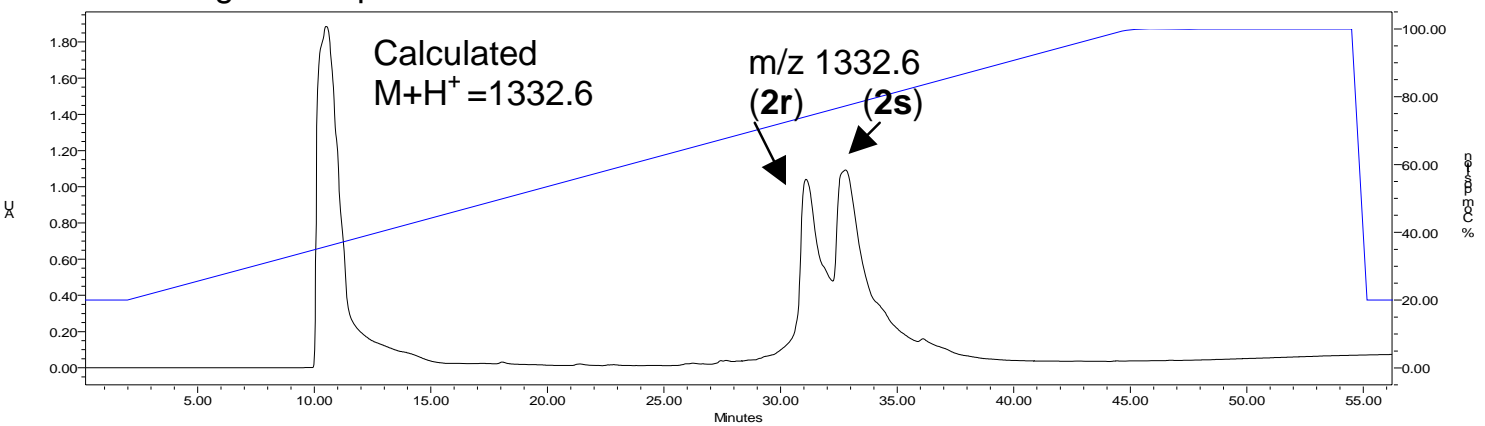

2t: D-Arg ${ }^{4}-$ Lys $^{6}-\mathrm{D}-$ Leu $^{10}$

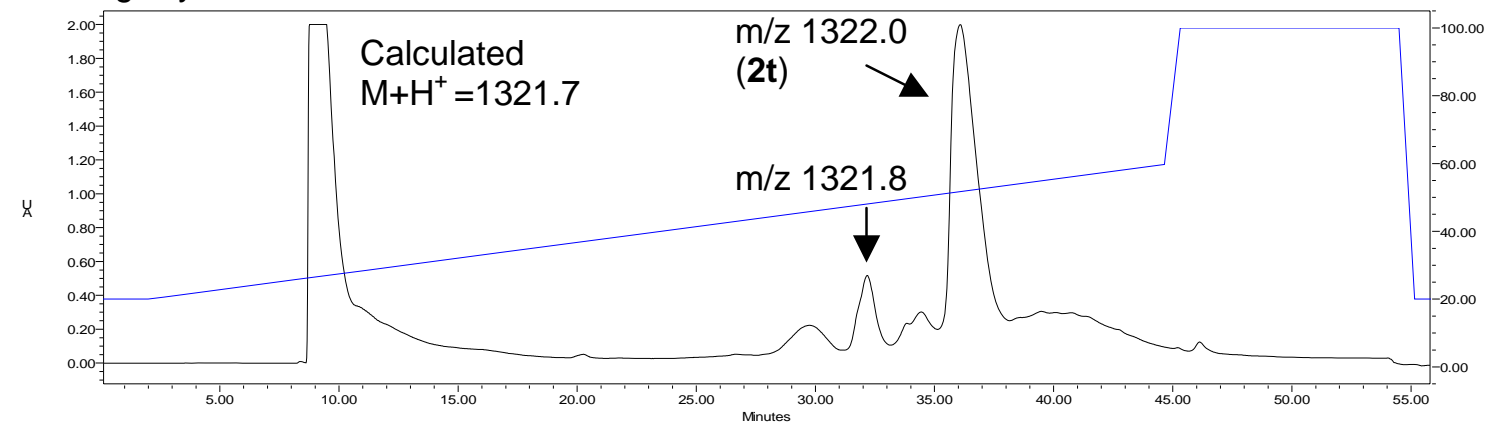


2u: D-Phe ${ }^{4}-D-P h e^{6}-S^{10}{ }^{10}$

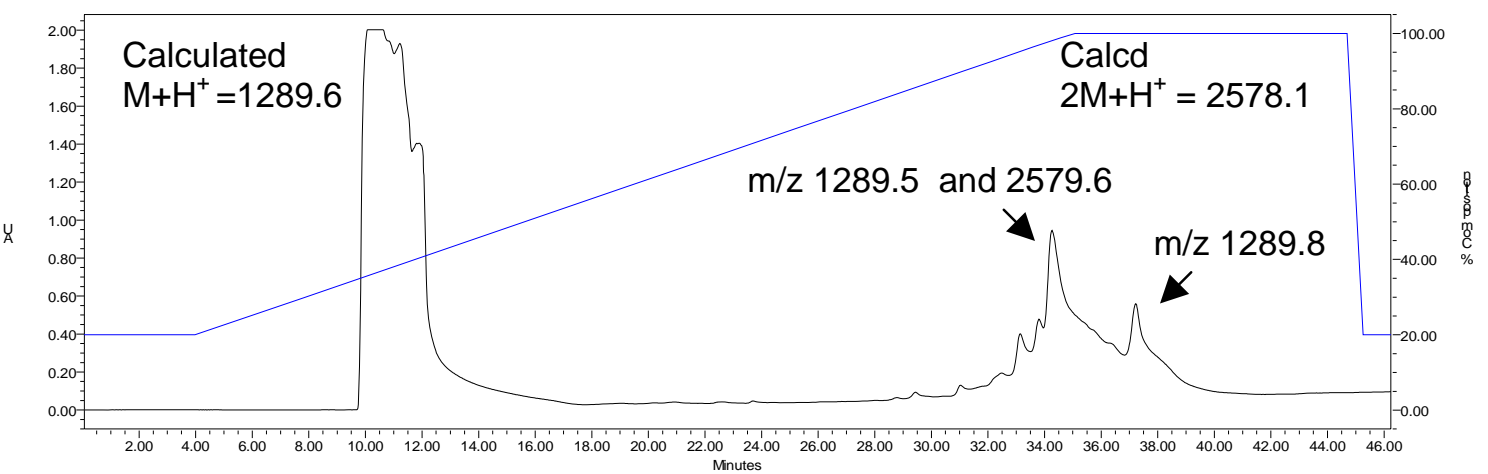

2x: D-Phe ${ }^{4}-$ Lys $^{6}-$ Gly $^{10}$

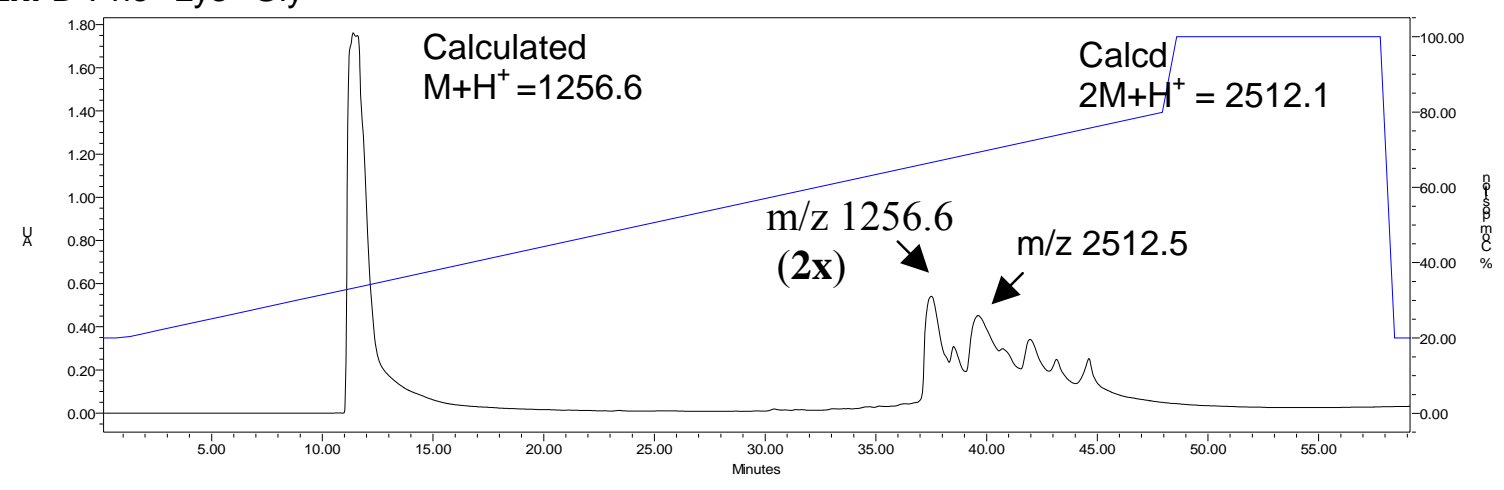


Figure S4. HPLC Chromatogram and MALDI-TOF MS of Purified Peptides

Peptide 2b

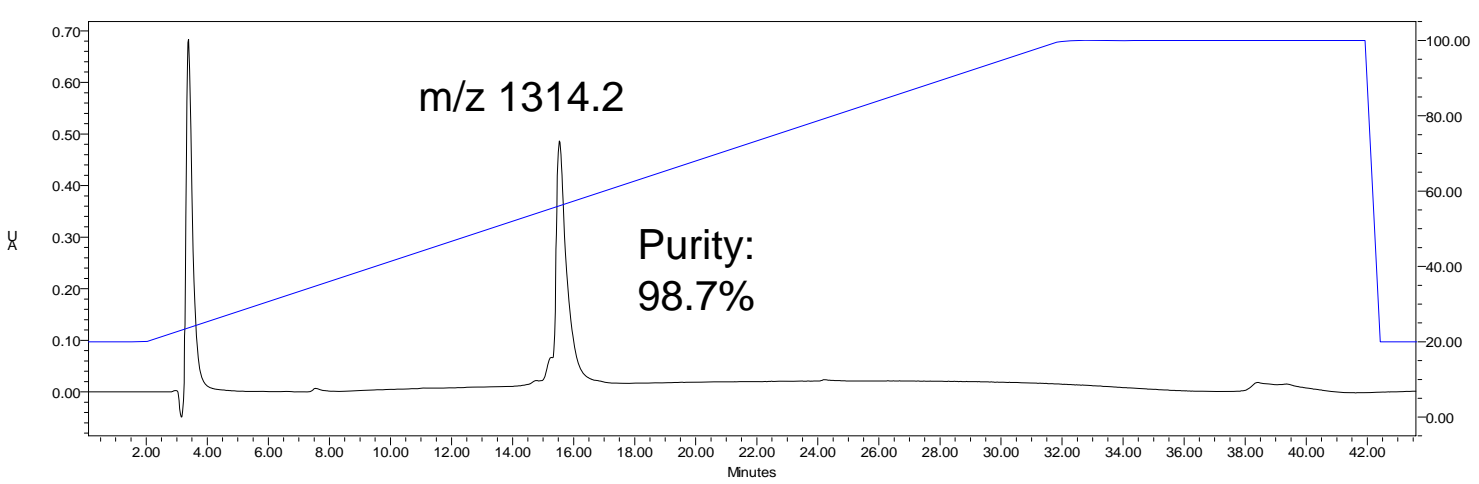

Peptide 8a
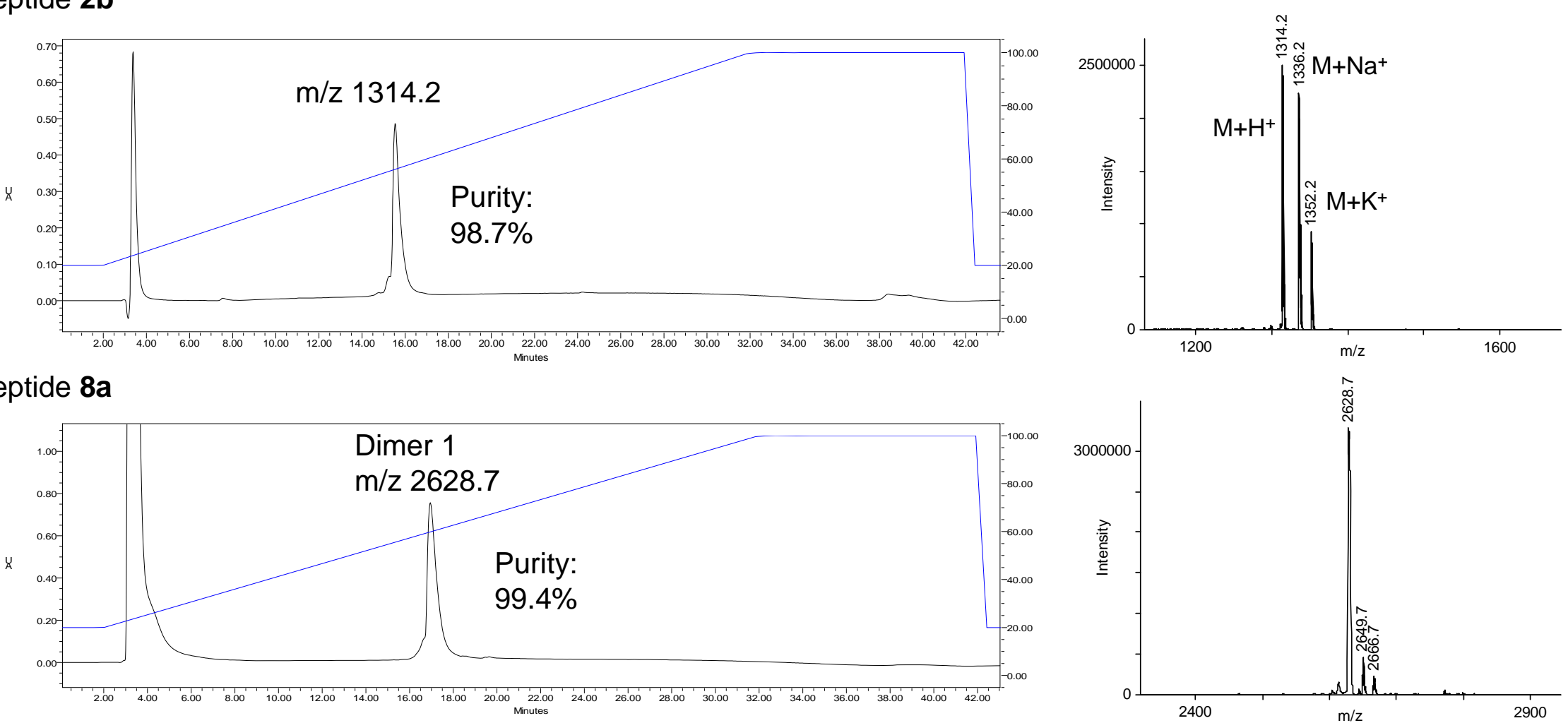

\section{Peptide 2d}
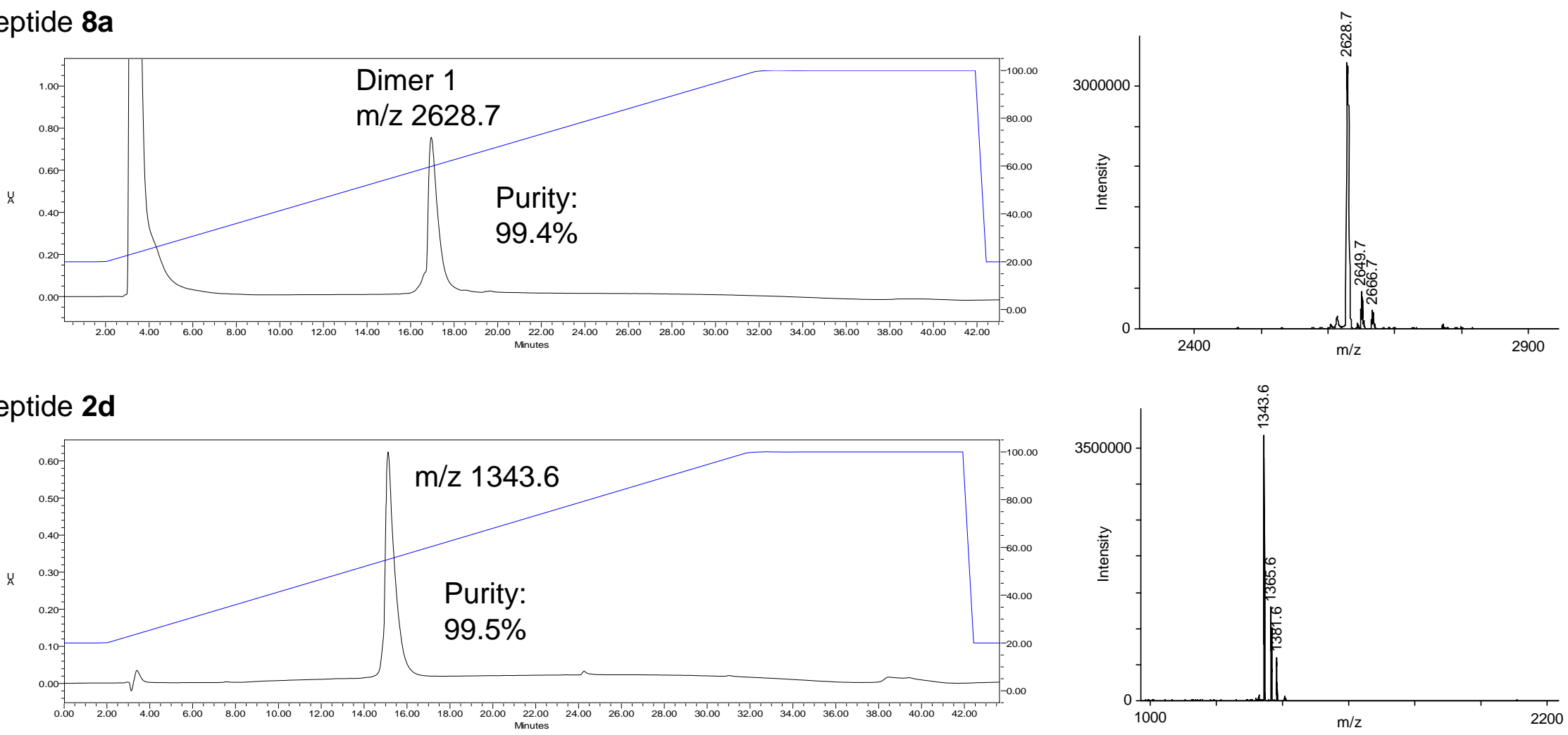


\section{Figure S4 cont'd}

Peptide 2e

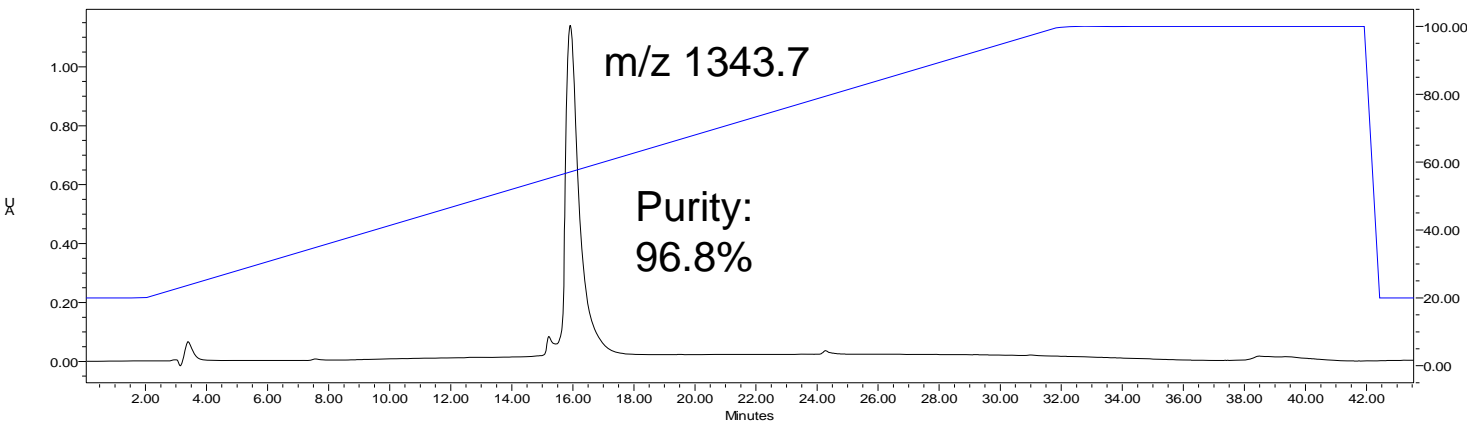

Peptide 2m

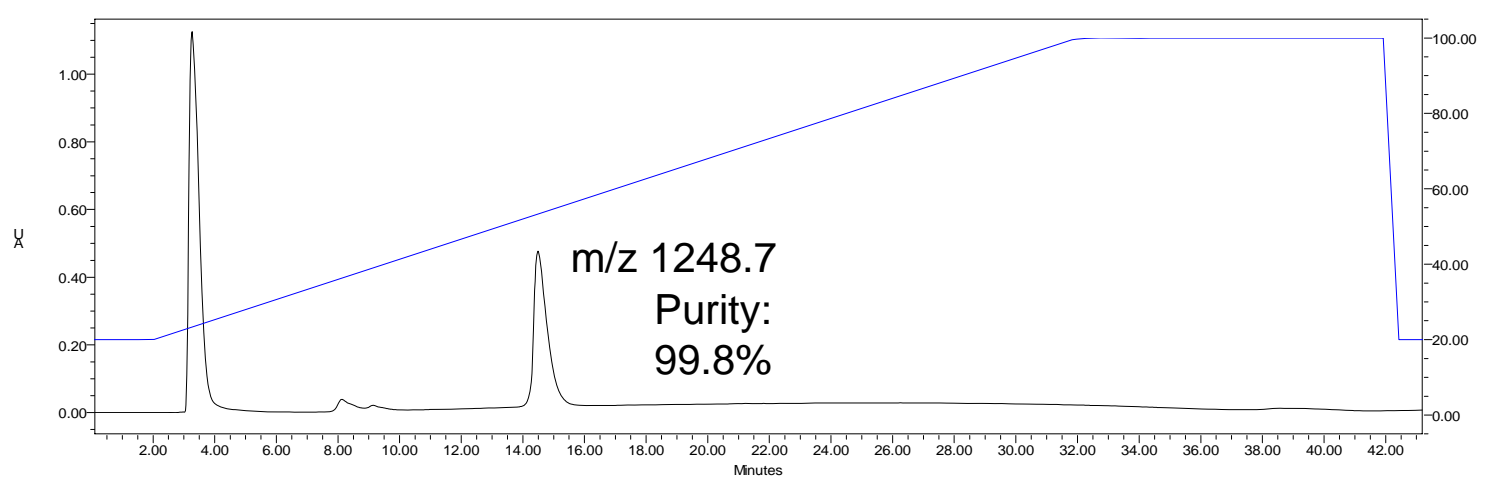

\section{Peptide $\mathbf{8 b}$}

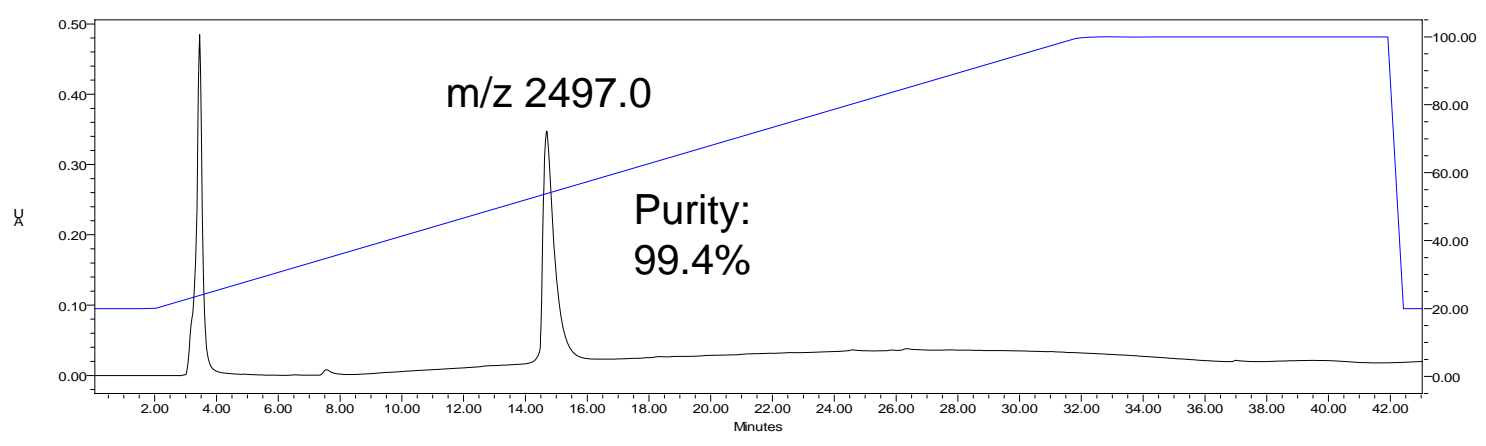

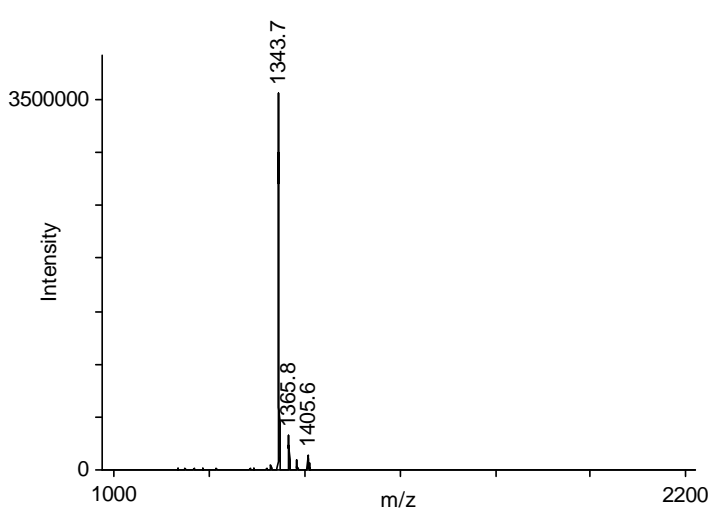
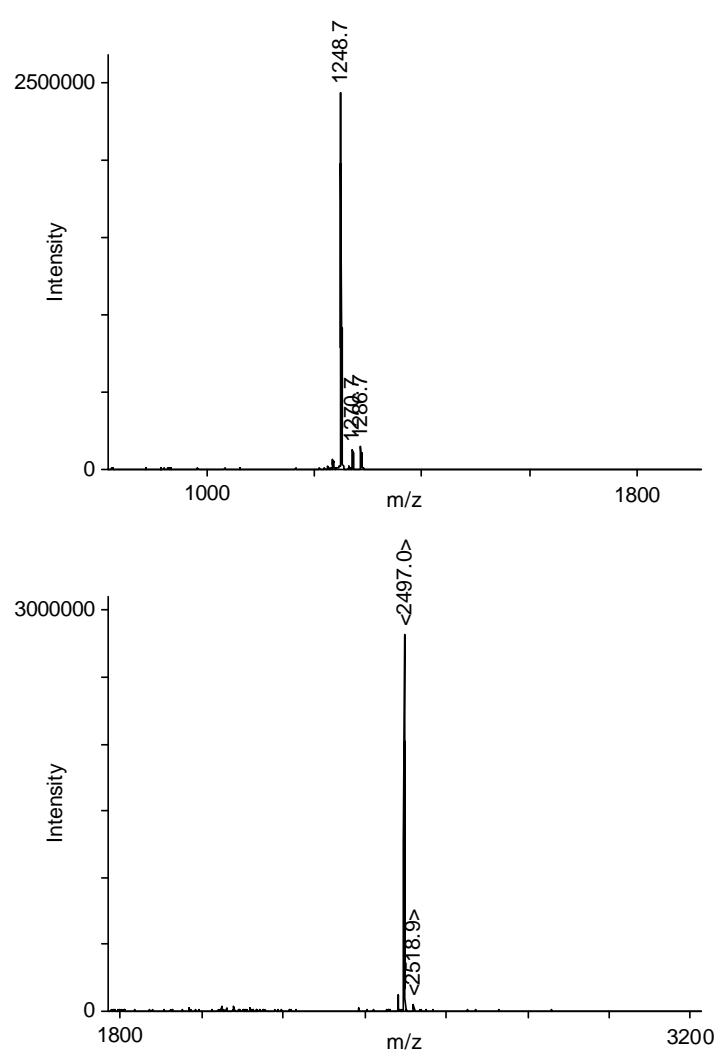


\section{Figure S4 cont'd}

\section{Peptide 2n}

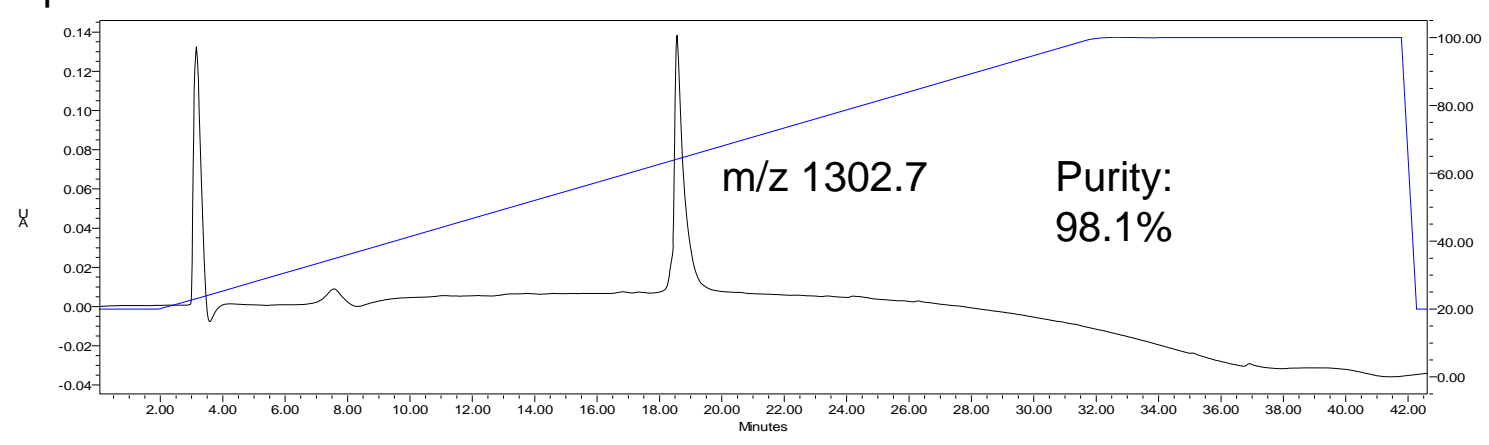

\section{Peptide 20}

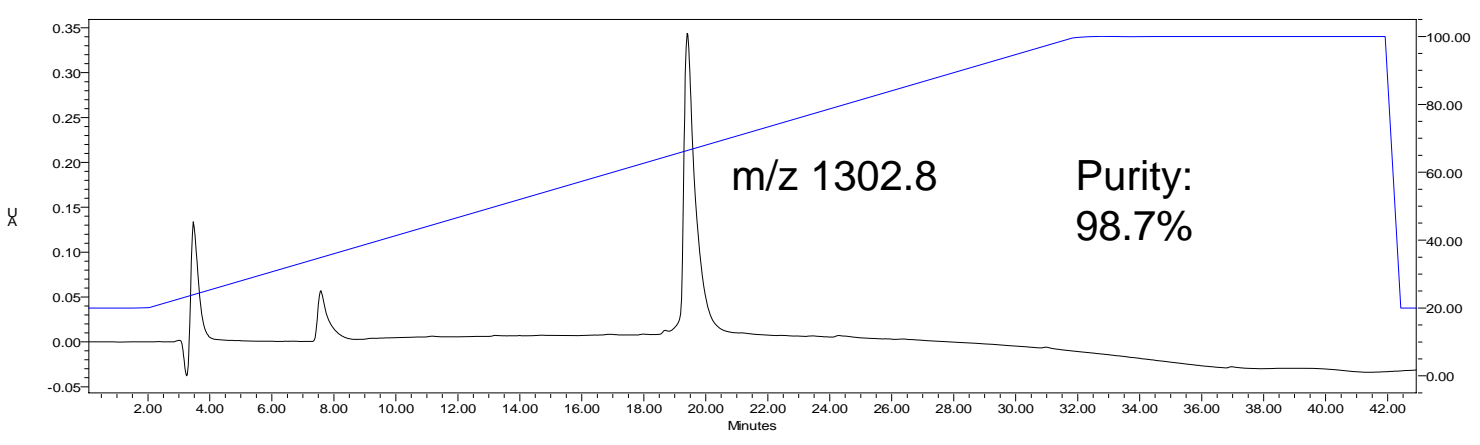

\section{Peptide 2p}

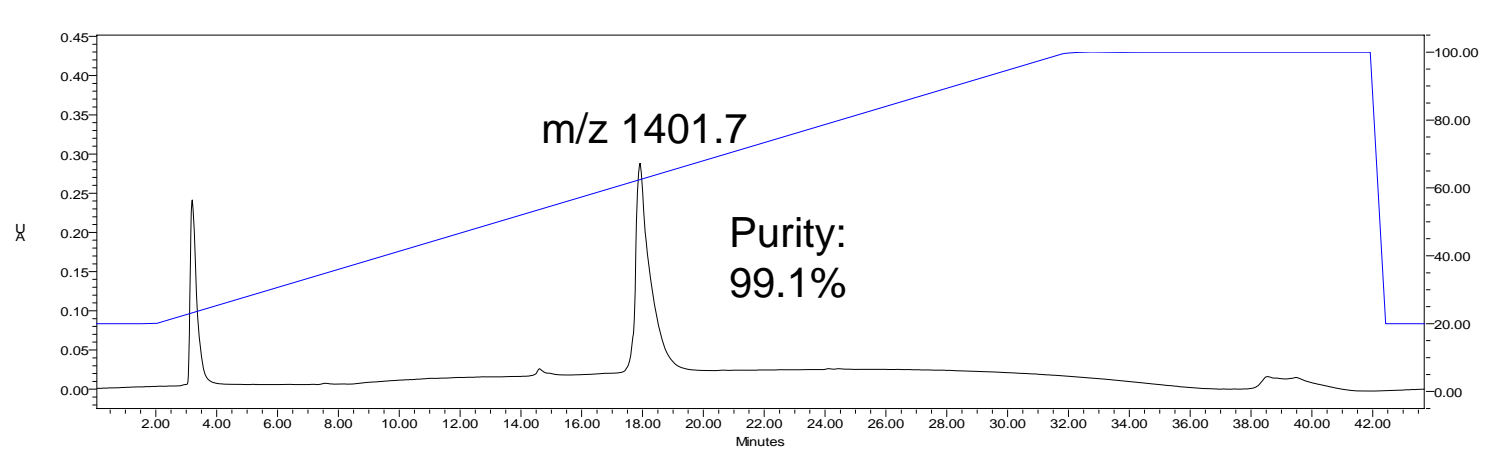

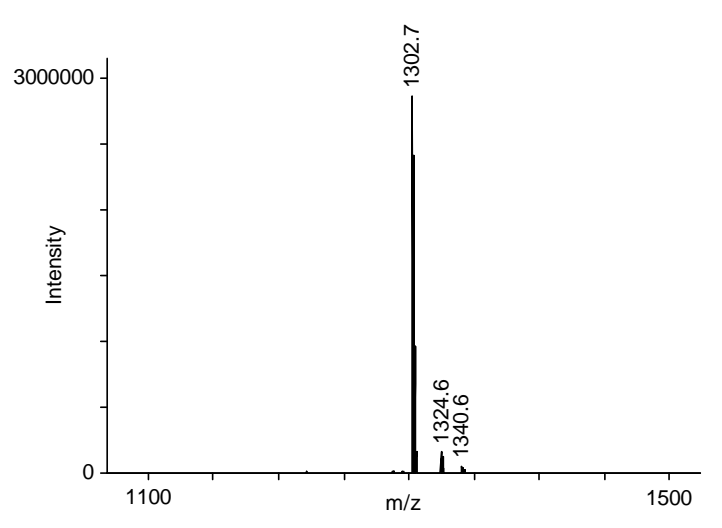
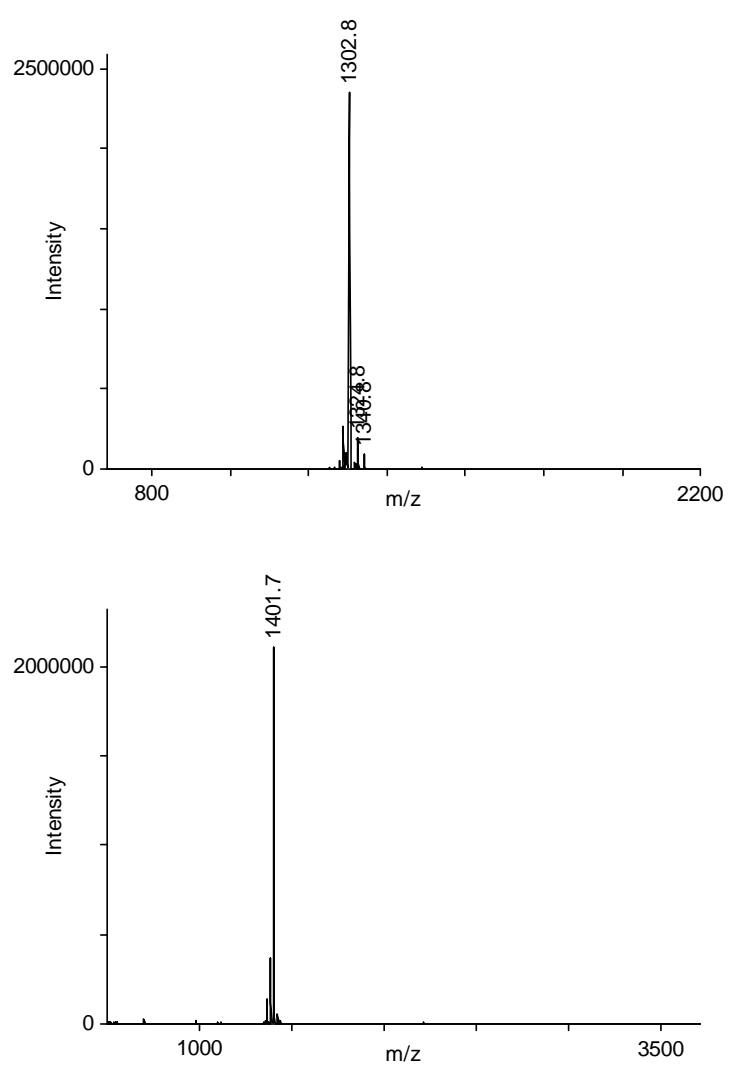


\section{Figure S4 cont'd}

\section{Peptide 2q}

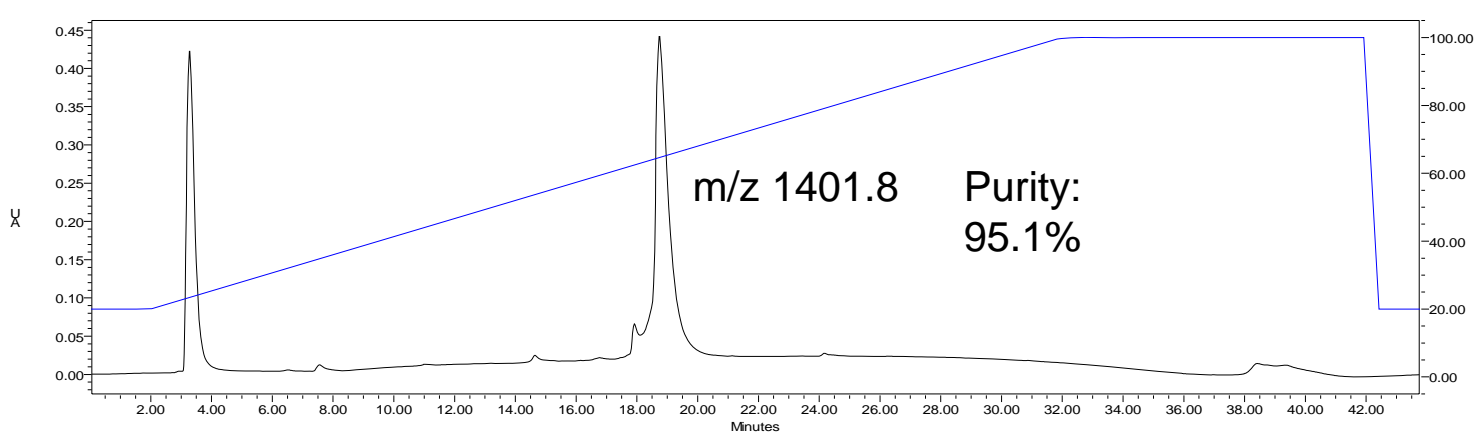

\section{Peptide 2r}

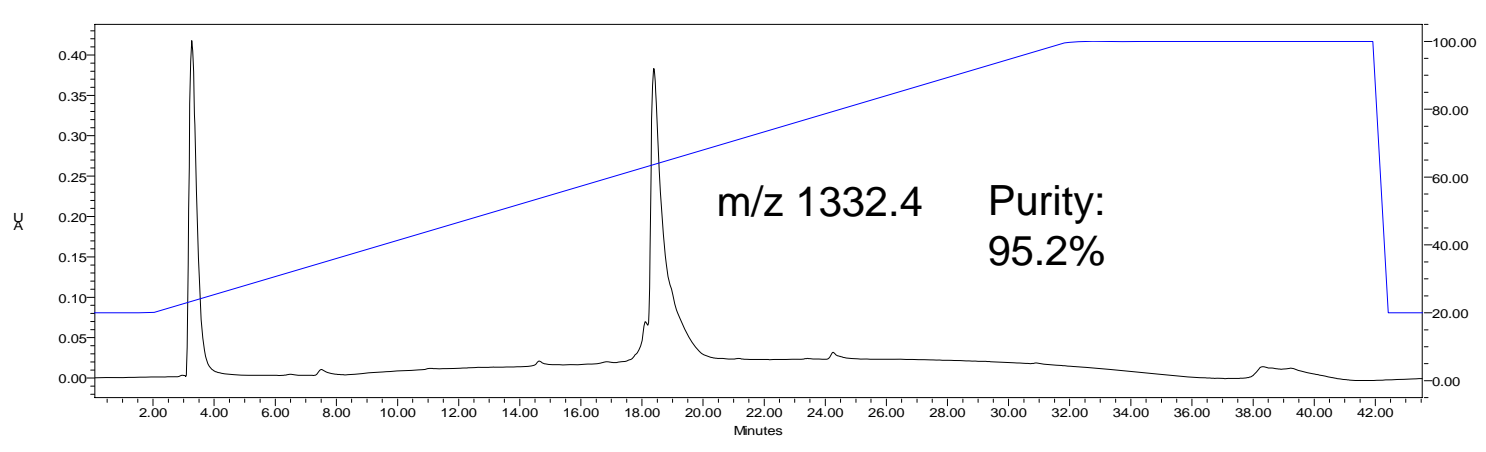

\section{Peptide 2s}

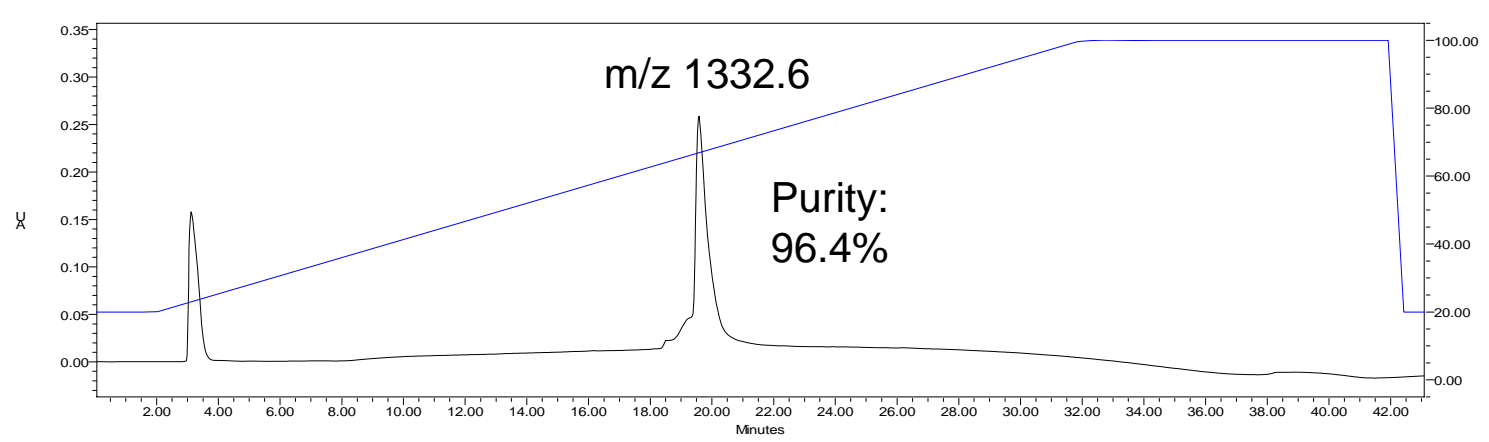

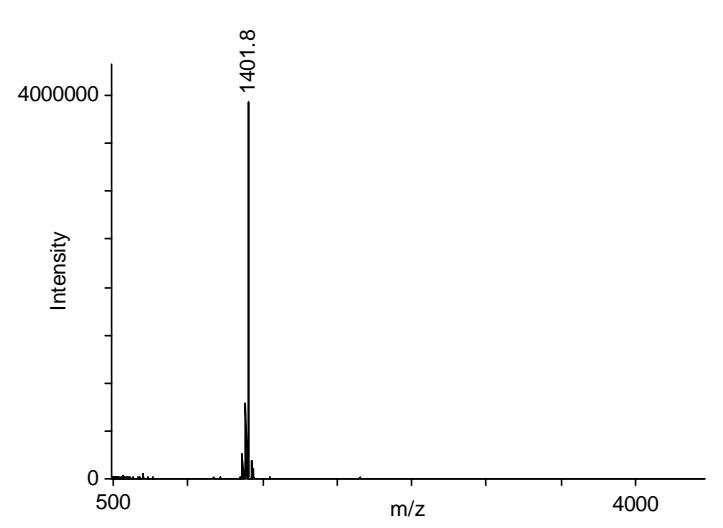
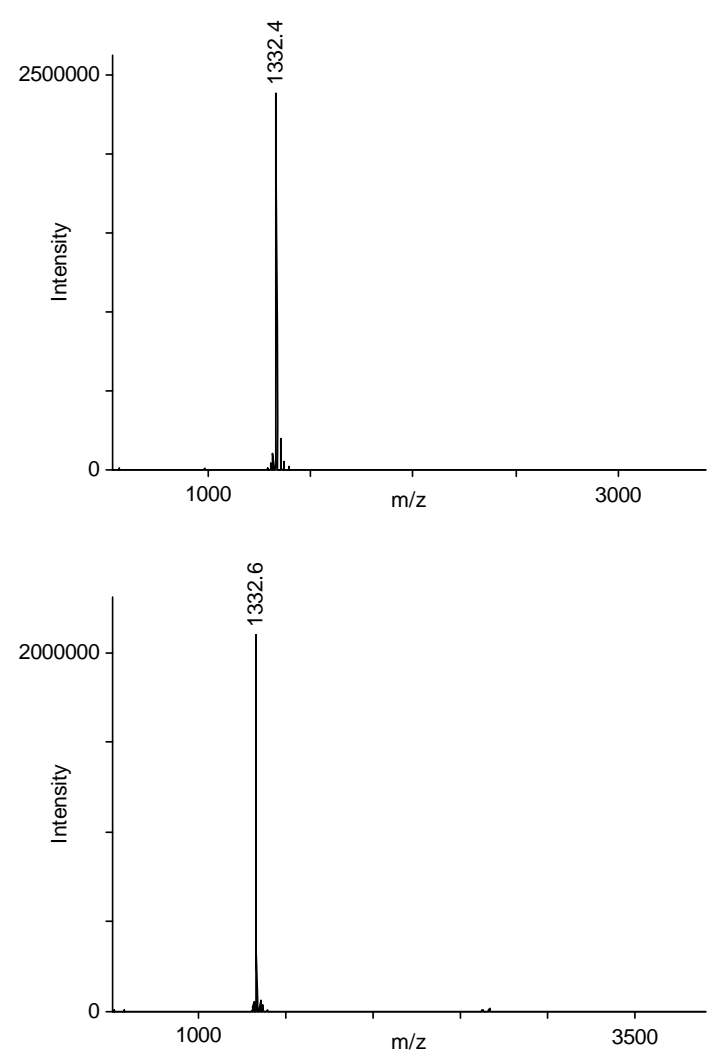


\section{Figure S4 cont'd}

\section{Peptide 2t}

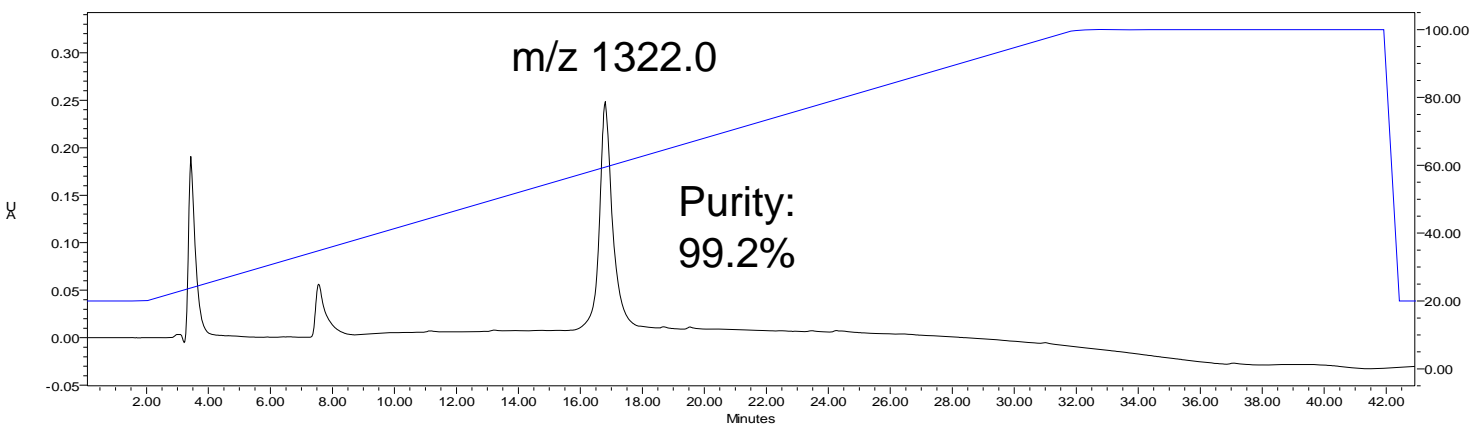

\section{Peptide 2x}

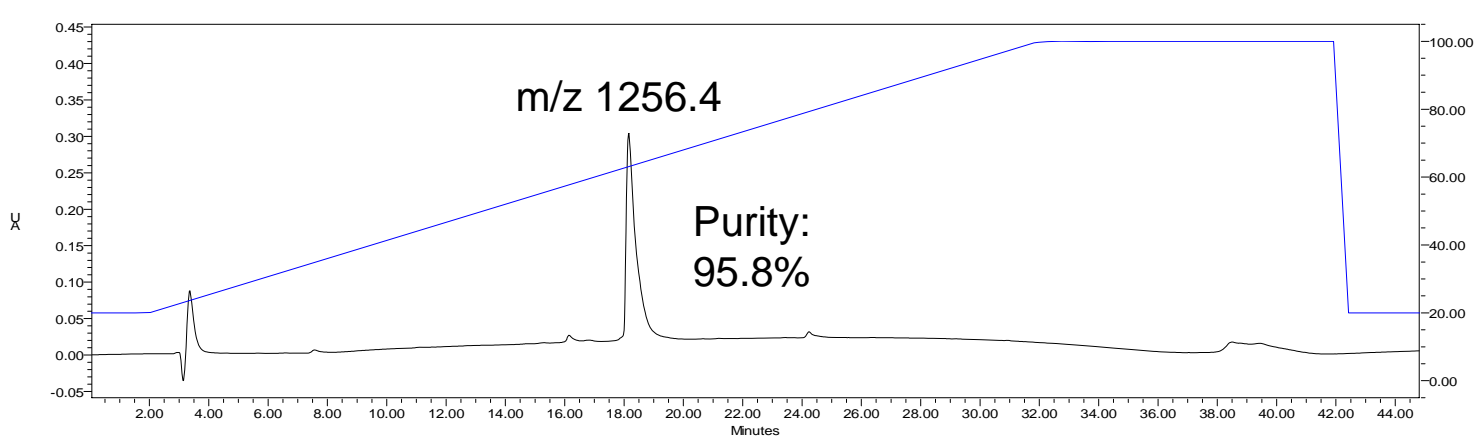

Tyrocidine A (1)

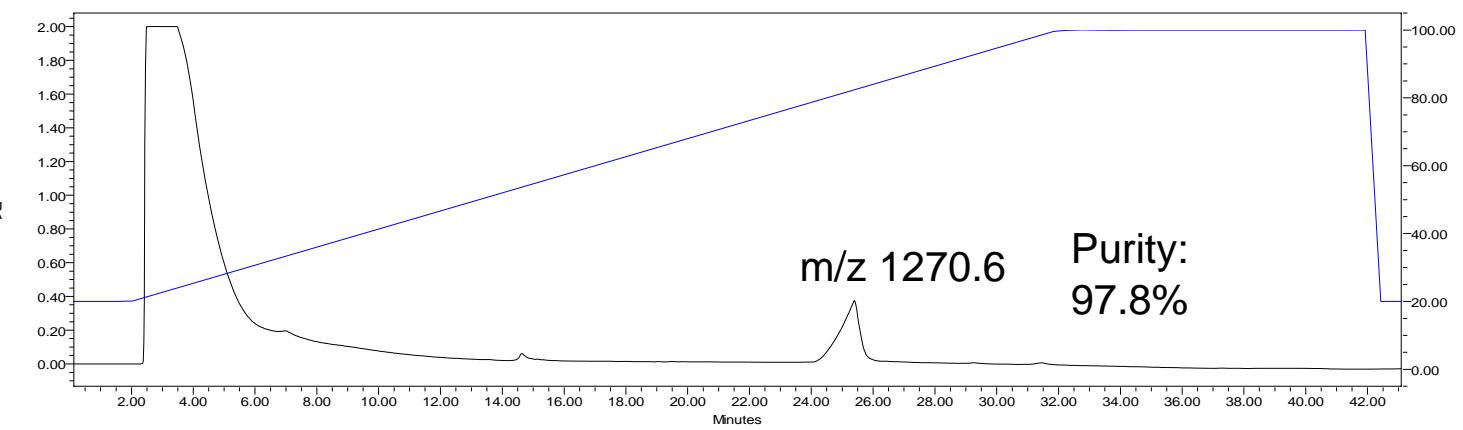

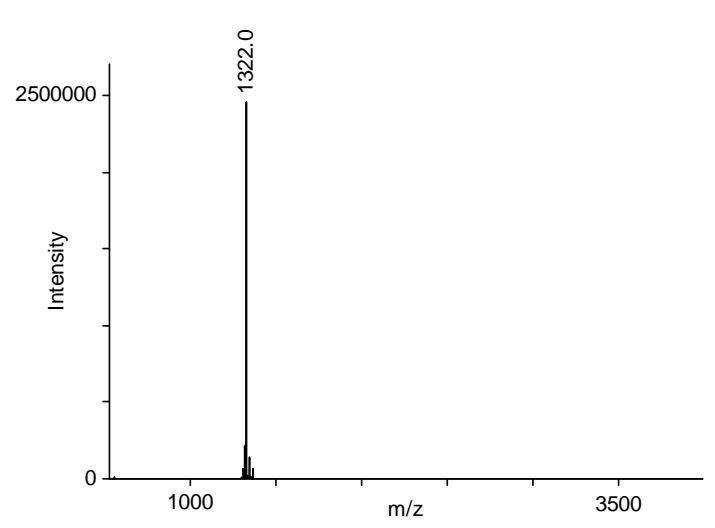
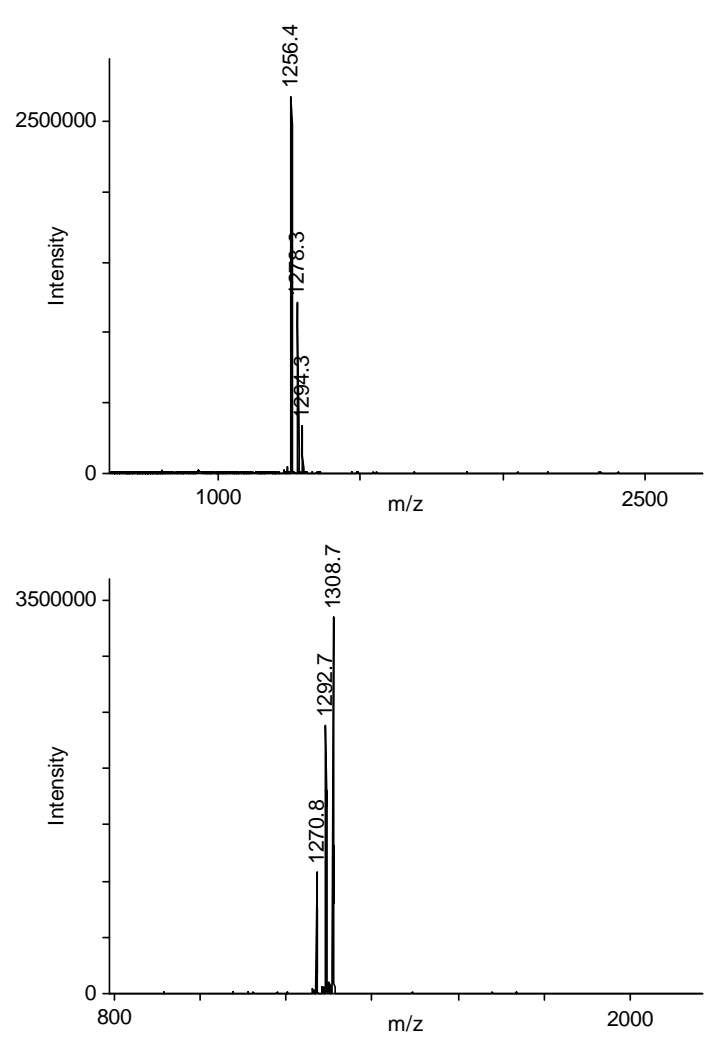